Esta obra está bajo una Licencia Creative Commons Atribución - No Comercial - Sin Derivar 4.0 Internacional

(c) $(1) \Theta(\Theta$

Justicia de género y valores emancipadores. Argentina y América Latina en perspectiva comparada internacional José Eduardo Jorge

Question, Vol. 1, N.ำ 62, e156, abril-junio 2019

ISSN 1669-6581 | https://doi.org/10.24215/16696581e156

http://perio.unlp.edu.ar/ojs/index.php/question

FPyCS | Universidad Nacional de La Plata

La Plata | Buenos Aires | Argentina

\title{
Justicia de género y valores emancipadores. Argentina y América Latina en perspectiva comparada internacional
}

\author{
Justice of gender and emancipatory values. Argentina and Latin \\ America in international comparative perspective
}

\author{
José Eduardo Jorge jjorge@perio.unlp.edu.ar \\ http://orcid.org/0000-0003-3596-1285 \\ Facultad de Periodismo y Comunicación Social; \\ Universidad Nacional de La Plata (Argentina)
}

\section{Resumen}

El debate público y legislativo sobre la interrupción voluntaria del embarazo en la Argentina dio fortaleza adicional a la movilización social feminista que había ganado renovado impulso desde 2015 con el surgimiento del movimiento \#NiUnaMenos. El trabajo se apoya en las teorías del Question, Vol. 1, N.․ 62, abril-junio 2019. ISSN 1669-6581

Instituto de Investigaciones en Comunicación | Facultad de Periodismo y Comunicación Social | Universidad Nacional de La Plata 
cambio cultural y en los estudios de género para analizar teórica y empíricamente la relación entre los valores prodemocráticos de "emancipación" o "autoexpresión" y las actitudes hacia la igualdad de género y las normas familiares y sexuales basadas en la libertad de elección y la igualdad de oportunidades, como son la aceptación del aborto y la homosexualidad. A partir de una muestra de 72 países, el artículo utiliza datos de la World Values Survey y Latinobarómetro para examinar la situación de 18 sociedades de América Latina en perspectiva mundial. Se indagan además empíricamente los factores que influyen en las políticas nacionales sobre legalización del aborto y violencia contra la mujer, entre ellos el impacto de los movimientos feministas, la representación parlamentaria de la mujer, la religión, los sistemas políticos y los valores culturales.

Palabras clave: Derechos de la mujer; valores emancipadores; cultura política; cambio cultural.

\section{Abstract}

The public and legislative debate on the voluntary termination of pregnancy in Argentina gave additional strength to the feminist social mobilization that had gained renewed momentum since 2015 through the emergence of the \#NiUnaMenos movement. This work relies on theories of cultural change and gender studies in order to analyze theoretically and empirically the relationship between pro-democracy "emancipation" or "self-expression" values and attitudes towards gender equality and family and sexual norms based on freedom of choice and equality of opportunities, such as the acceptance of abortion and homosexuality. The article uses a sample of 72 countries with data from the World Values Survey and Latinobarómetro to examine the position of 18 Latin American societies in global perspective. The factors influencing national policies on the legalization of abortion and violence against women are also empirically investigated, including the impact of feminist movements, the parliamentary representation of women, religion, political systems and cultural values.

Keywords: Women's rights; emancipative values; political culture; culture change.

Cuando en la madrugada del 9 de agosto de 2018 el Senado rechazó el proyecto de ley de interrupción voluntaria del embarazo con media sanción de Diputados, Ixs promotorxs de la iniciativa -según el lenguaje inclusivo que ganó difusión en esas jornadas- y todxs (o todes) aquellxs, en su mayoría mujeres, que por miles lo habían impulsado desde las calles, 
recibieron el previsible desenlace con sentimientos encontrados. El recorrido logrado en el Congreso y el grado en que el tema del aborto quedó instalado en la sociedad argentina luego de seis meses de debate era casi impensable no mucho antes.

No solo la cuestión del aborto legal, seguro y gratuito había dejado de ser un tabú y un estigma: había entrado en forma irreversible en la agenda política y electoral. Y el nivel de movilización alcanzado -los simbólicos pañuelos verdes se volvieron una presencia recurrente en los espacios públicos- anunciaba la continuidad de la campaña.

Los sucesos resonaron entre los grupos defensores de los derechos de la mujer de la región y el mundo y en los principales medios del exterior. Confluían con el ascenso de lo que algunos consideran un resurgimiento del concepto de "patriarcado", asociado a una "cuarta ola" feminista (1) (Reger, 2015; Snyder, 2015; Freedman, 2002) de la que serían expresiones nuestro movimiento \#NiUnaMenos y el más reciente \#MeToo.

Se anticipaba además que una eventual aprobación de la ley tendría repercusiones en toda América Latina, donde solo Uruguay, Cuba y Guyana permiten el aborto por razones distintas del riesgo de vida de la madre, violación o grave malformación del feto (World Health Organization, 2018). Las leyes del resto de los países latinoamericanos se califican, en perspectiva global, como "altamente restrictivas" (Singh, Remez, Sedgh, Kwok y Onda, 2018: 50). En República Dominicana, El Salvador, Honduras, Nicaragua, Haití y Surinam la práctica está prohibida sin excepciones.

De las 125 naciones del mundo con estas restricciones legales, más del 90\% son sociedades en desarrollo con altas tasas de fertilidad, embarazos no deseados, abortos inseguros -que afectan principalmente a las mujeres pobres- y mortalidad materna (Ibídem: 28-40; United Nations, 2017, 2014). Las notas opuestas distinguen a las sociedades prósperas, donde, con unas pocas excepciones, la ley habilita a la mujer a interrumpir su embarazo con solo requerirlo -o al menos, en algunos países, por razones socioeconómicas a fin de preservar su salud física o mental-, aunque casi siempre con límites de tiempo de gestación. Este mismo tipo de leyes rige en varias naciones asiáticas -entre ellas China, India y Vietnam- y de la ex Unión Soviética y su área de influencia.

Pero si el debate en la Argentina tuvo proyección global fue porque el estado de la cuestión en el mundo, pese a una tendencia lenta e irregular hacia la liberalización, sigue siendo alarmante para los derechos de la mujer.

Aunque la legislación sobre el aborto pasó desde principios del siglo XX por varias revoluciones, la más profunda ha sido el giro hacia los derechos humanos (Cook, Erdman y Dickens, 2014). A medida que la igualdad entre mujeres y varones avanza en una sociedad, afirman Cook y Dickens (2003: 7), "es de prever que la cuestión del aborto evolucione de su 
encasillamiento penal o en el código penal a otro vinculado a la salud o la legislación de salud pública, y finalmente a su inmersión en las leyes que sirven a los objetivos de los derechos humanos, la justicia social y la dignidad individual del control sobre el propio cuerpo", este último el "sine qua non de los derechos en general" (Asal, Brown y Gibson Figueroa, 2008: 266).

Hoy, sin embargo, el mundo presenta "una plétora de leyes y restricciones intrincadas" que "no tiene ningún sentido desde el punto de vista legal o de la salud pública" (Berer, 2017). Está bien documentado que los obstáculos legales no eliminan el aborto, sino que lo vuelven más riesgoso. Se estima que estas prácticas inseguras producen $13 \%$ de las muertes maternas a nivel global y $12 \%$ en América Latina y el Caribe (World Health Organization, 2011: 28).

Hay además gran disparidad en la forma en que los países implementan sus leyes. Con frecuencia la introducción de reformas legales progresistas no va acompañada de su ejecución plena y algunas naciones con leyes liberales han reintroducido impedimentos (Singh et al., 2018: 17). La falta de servicios hospitalarios y el estigma social vinculado a menudo con el aborto siguen empujando a muchas mujeres a buscar intervenciones riesgosas (lbídem: 30). En Argentina, la Corte Suprema, en el fallo que en 2012 precisó el alcance de los abortos no punibles, fijó pautas para remover las barreras más frecuentes a su realización -como la judicialización y las dilaciones en las prácticas médicas- y exhortó a la Nación y a las provincias a ejecutar protocolos hospitalarios. Sin embargo, la mayoría de las jurisdicciones no se han adecuado a la sentencia (Amnistía Internacional et al., 2018).

\section{Contrastes en las políticas sobre los derechos de la mujer}

La legislación y las políticas sobre el aborto son un caso agudo de los fuertes contrastes que presenta el universo de los derechos de la mujer. Estos pueden ser considerados una subcategoría de la "justicia de género", que abarca a todas las personas "construidas por las instituciones de género" (Htun y Weldon, 2018: 2).

En el marco de una tendencia general a la igualación del estatus legal de mujeres y varones en muchas áreas, los avances y retrasos en políticas sobre temas específicos -derecho de familia, igualdad laboral, licencias por maternidad y paternidad, violencia contra la mujer y cuotas electorales, entre otros- varían sustancialmente no solo entre los países, sino también dentro de cada uno. Argentina, por ejemplo, ha sido pionera en la región en adoptar normas para aumentar la representación política de la mujer, pero está muy rezagada en materia de 
interrupción voluntaria del embarazo. Situaciones de este tipo se repiten en muchas otras sociedades.

La razón de estos patrones irregulares de continuidad y cambio reside, para Htun y Weldon (2018: 8-22), en que las diferentes clases de derechos de la mujer cuestionan aspectos distintos de las relaciones sociales prevalecientes, en modos diversos y con desigual intensidad. No todos los legados históricos, instituciones, condiciones del contexto y actores sociopolíticos de una sociedad son igualmente relevantes para cada área de derechos.

Las políticas pueden clasificarse, según estas investigadoras, a lo largo de dos dimensiones. Una las cataloga en función de si avanzan derechos de la mujer como grupo de "estatus" o de "clase", buscando cambiar su posición social o legal o aspectos de las relaciones socioeconómicas. Otra apunta a si las acciones promotoras cuestionan o no las tradiciones culturales, doctrinas religiosas o discursos sagrados. La combinación de estas dos dimensiones define cuatro tipos de políticas. El aborto legal es "doctrinal" y de "estatus". Las medidas sobre violencia contra la mujer, cuotas de género e igualdad laboral son también de "estatus", pero "no doctrinales". Las licencias por maternidad y el aborto gratuito son ambos de "clase", pero el segundo es "doctrinal" y las primeras no.

Esta perspectiva descansa en parte en el concepto -de uso extendido en los estudios de género- de "interseccionalidad", que aborda la categoría "mujer" con sus subdivisiones de clase, raza, etnicidad, orientación sexual y similares. "Las oportunidades de las mujeres, sus posibilidades de bienestar y el respeto que reciben de los otros están conformados por la intersección de múltiples posiciones sociales" (Ibídem: 10; Collins y Chepp, 2013). Como sucede con las restricciones al aborto, muchas injusticias son infligidas a las mujeres como tales -no solo por ser pobres o pertenecer a una etnia-, pero no todas las sufren del mismo modo o con la misma intensidad.

Estos criterios son valiosos para identificar posibles factores que dificultan o facilitan las políticas públicas de promoción de derechos. Apoyándose en un exhaustivo estudio transnacional, Htun y Weldon (2018) plantean y contrastan empíricamente un número de hipótesis sobre los actores e instituciones más relevantes para cada una de sus categorías de política. Para las de "estatus", sería clave la existencia de un movimiento social feminista "fuerte y autónomo"; para las de "clase", la presencia de partidos progresistas. La religión es una poderosa influencia negativa en el campo de las acciones "doctrinales" (Ibídem: 17).

El resultado del tratamiento legislativo del aborto en Argentina ha sido contrastado con lo sucedido poco antes en otra sociedad católica: Irlanda (2). En marzo de 2018, una mayoría abrumadora de irlandeses votó en un referéndum el fin de la prohibición casi total de esa práctica que hacía de esta nación un caso desviado en Europa. La decisión del Senado de 
nuestro país se atribuyó a la ascendencia que, como en toda América Latina, conserva la Iglesia católica (más aún en las provincias del interior, con mayor representación en la cámara alta que en la de diputados).

En la investigación comparada entre países, el catolicismo como religión predominante tiene una asociación negativa con el aborto legal. Analizando los cambios de las políticas nacionales entre 1960 y 2009, Boyle, Kim y Longhofer (2015) concluyen que un primer paso a la despenalización por razones distintas del riesgo de vida de la madre -normalmente por violación- tendió a darse en las naciones que, a igualdad de ingreso per cápita y gasto estatal, poseen mayor proporción de médicos por habitante y de mujeres en el parlamento. La tradición católica no mostró una relación negativa con esta primera apertura, pero sí con la legalización, en general posterior, por anomalías del feto y riesgos en la salud mental de la embarazada.

Htun y Weldon (2018: 201-228) hallan que varios "factores religiosos" operan como barreras al avance de la mujer en los campos doctrinales del aborto legal y el derecho de familia. Comprueban el peso adverso de la religiosidad de la población, las denominaciones católica e islámica y los partidos confesionales, pero subrayan el de la "institucionalización política de la autoridad religiosa", que depende del grado en que el Estado sostiene el culto o es independiente de él.

Las políticas nacionales sobre los derechos de la mujer suelen ser influidas, como sucede en otras áreas, por el surgimiento de un estándar o enfoque compartido en el nivel internacional por una masa crítica de expertos, ONG, organismos multilaterales y otros actores (Dobbin, Simmons y Garrett, 2007). La violencia contra la mujer es motivo de un consenso creciente, que se extiende a las causas y las acciones más adecuadas de prevención y asistencia. Si bien no fue reconocida como prioridad por la Convención de la ONU sobre la Eliminación de Todas las Formas de Discriminación Contra la Mujer (CEDAW) de 1979, a partir de la Conferencia de Viena (1993) se la considera una violación de los derechos humanos -la más generalizada, cuya expresión extrema es el femicidio-. Y en 1995, el plan de acción aprobado por la Conferencia sobre la Mujer en Pekín fijó un acuerdo para abordar el problema mediante un abanico de políticas.

Pero en la cuestión del aborto no ha surgido un enfoque único. El tema sigue generando controversia y los modelos de política son disputados. Boyle et al. (2015) sugieren que las pasadas discusiones entre las ONG transnacionales de la mujer y la Iglesia católica en los encuentros de la ONU acrecentaron la influencia de la perspectiva científico-médica por encima de la feminista de los derechos y la católica de la "familia natural", aunque el impacto de cada una de estas tres visiones en un país depende del peso de los distintos actores locales. 
Los movimientos de la "segunda ola" feminista ya eran en los 70 un fenómeno global. Hacia los 90, no solo habían incidido en los resultados de las Conferencias de la Mujer de la ONU -como el plan de acción de Pekín-, sino instalado su agenda en encuentros sobre cuestiones antes consideradas neutras desde la perspectiva de género, como los derechos humanos, el desarrollo, el crecimiento de la población y el medio ambiente (Friedman, 2003; Freedman e Isaacs, 1993). Pero a la vez que transformaba la visión de los temas globales, el movimiento vio surgir, especialmente en Pekín y en la conferencia sobre Población y Desarrollo de El Cairo en 1994 (McIntosh y Finkle, 1995), la fuerte oposición de una coalición liderada por el Vaticano -observador permanente de la ONU- e integrada por ONG conservadoras y religiosas y un número de países católicos e islámicos, entre ellos Argentina y otros latinoamericanos. Esta alianza impugnó el cuestionamiento de las relaciones tradicionales de género en la organización familiar y en el control de la sexualidad y el rol reproductivo de la mujer (Friedman, 2003: 323-27; Glendon, 1996; Buss, 1998).

Htun y Weldon $(2012,2018)$ postulan que la acción de un movimiento feminista "fuerte y autónomo" en el nivel nacional es crítica para que el Estado adopte políticas que avancen el estatus social de la mujer, como son las que abordan la violencia de género y el aborto legal. "Autonomía" significa que esos grupos son independientes del Estado y de otras asociaciones cuyo "propósito central" no es la posición social de la mujer, entre ellas los partidos y aún las organizaciones de derechos humanos. Para estas autoras, los gobiernos responden sobre todo a esa movilización de la sociedad civil, cuyo influjo sería más relevante que el de la sola presencia femenina en cargos parlamentarios y ejecutivos, un factor destacado por otros trabajos (Boyle et al., 2015; Asal et al., 2008).

Los movimientos propiamente "feministas" "buscan cambiar el estatus de la mujer y cuestionan su subordinación a los varones y las jerarquías de género que la sustentan" (Mazur, McBride y Hoard, 2016: 653; Beckwith, 2013). Se distinguen en esto de las organizaciones de mujeres con otros objetivos.

\section{Impacto del cambio cultural}

Con toda la importancia que tienen las reformas legales y la adopción de políticas públicas a fin de impulsar la igualdad y la autonomía para la mujer, el impacto de la cultura no puede ser omitido. Nuestras percepciones sobre la división apropiada de roles en la familia, el lugar de trabajo, la esfera política y otros ámbitos son estructuradas por los valores, creencias y normas culturales predominantes en nuestra sociedad. 
El "género" de un individuo no es una esencia determinada por la biología. Remite a roles y atributos socialmente construidos -en general en términos binarios- y a conductas aprendidas en respuesta a las expectativas sociales. Es, dice Ridgeway, "un sistema de prácticas sociales" que "constituye categorías de sexo distintivas y diferenciadas, clasifica en ellas a las personas y organiza las relaciones interpersonales sobre la base de las diferencias definidas por esas categorías" (2011: 9).

En los países donde prevalecen valores tradicionales, apuntan Inglehart y Norris (2003: 9), las mujeres "no solo ven sus oportunidades limitadas por la sociedad, sino que tienden a limitarse a sí mismas". No es muy probable que el Estado adopte allí políticas progresistas o que éstas sean eficaces. Incluso en naciones con grandes movimientos feministas, muchas mujeres sexualmente violentadas no se consideran víctimas de una violación, frente a lo que ven como "un hecho de la vida" (Htun y Weldon, 2012: 553).

Una "cultura de igualdad de género", sin embargo, "provee un clima en el que es más probable que los derechos legales de jure se traduzcan en la práctica en derechos de facto" (Inglehart y Norris: 8). El cambio cultural -que entraña un giro en las actitudes, valores y creencias de mujeres y varones- surge como una "condición necesaria", aunque no suficiente, para alcanzar la igualdad de hecho. Ese cambio "sienta las bases para la movilización de las organizaciones de la mujer y el apoyo amplio a las políticas públicas que refuerzan, consolidan o aceleran el proceso" (Ibídem: 9).

El giro en la cultura es producto a su vez del desarrollo económico y humano y tiene lugar al lento ritmo del reemplazo inter-generacional (Inglehart y Welzel, 2005; Jorge, 2018b, 2016b, $2015,2010)$. Si la industrialización cercena el poder de la autoridad tradicional, el desarrollo posindustrial debilita todas las formas de autoridad política, religiosa y social -incluido el patriarcado-, debido al ascenso, en la sociedad y el individuo, de un sistema de valores de "autoexpresión" que enfatiza la libertad de elección y la igualdad de oportunidades.

El aspecto mejor documentado del surgimiento de este sistema -con series de datos que se remontan a los 70 (Inglehart, 2008)- es el giro desde los valores "materialistas", centrados en la seguridad física y económica, a los "posmaterialistas", que priorizan las necesidades de "autorrealización" de las personas (Inglehart, 1990: 131). Pero la mutación ha alcanzado a todos los dominios de la sociedad y la cultura (Inglehart, 1997). El feminismo es una de sus manifestaciones. A partir de los 60 , ganaron cada vez más importancia formas de participación política autodirigida que desafían a las elites y una miríada de movimientos sociales, como los que defienden la igualdad de género, la libre elección de la orientación sexual y el estilo de vida, el medio ambiente y los derechos de minorías o grupos marginados u oprimidos. 
Estas transformaciones adquirieron máxima expresión en los países industrializados, donde, por varias décadas desde 1945, un crecimiento económico sostenido, combinado con las políticas redistributivas del Estado de Bienestar, permitió que las nuevas generaciones crecieran en un entorno de "seguridad existencial" sin precedentes. Un cambio de valores intergeneracional tuvo lugar también en los estratos más seguros de las sociedades de ingreso medio, pero según Inglehart (2018: 32) los niveles de posmaterialismo en los países de América Latina relevados por la World Values Survey son hoy, en promedio, similares a los de Europa en los 70.

Una visión complementaria enfoca el rasgo "emancipador" de los valores de autoexpresión. El desarrollo humano envuelve un proceso de "empoderamiento" al "emancipar a las personas de la dominación externa" (Welzel, 2013: 278). Esto requiere "libertades iguales", que se consagran a través de los derechos de los ciudadanos. La revolución de derechos de los últimos años, que abarca a muchos grupos postergados, entre ellos las mujeres -el más grande de todos- y la comunidad LGBTQ+, representa "la tendencia hacia el empoderamiento humano en el dominio de las instituciones" (Ibídem: 279; Jorge, 2016b). Los movimientos sociales que demandan esos derechos apelan a los valores de autoexpresión para justificarlos. No todos los aspectos del cambio cultural -ni su impacto en las instituciones- han seguido la misma trayectoria. En cada país, estos procesos pueden ser retrasados o acelerados por específicos legados religiosos, tradiciones históricas, movimientos civiles, partidos y dirigentes políticos, la justicia, los medios y otros factores. El grado en que los argentinos han justificado el aborto -al menos antes del debate de 2018- ha estado durante décadas bien por debajo del nivel de aprobación de la homosexualidad (Jorge, 2018a, 2015, 2011). La Campaña Nacional por el Derecho al Aborto no cesó de presentar un proyecto de ley desde 2007, pero la problemática no lograba superar las barreras que impedían su acceso a la discusión pública. En contraste, el país fue uno de los primeros en contar con una ley de matrimonio igualitario y una de las más progresistas del mundo sobre identidad de género.

Las naciones industrializadas han sufrido desde los 90 un alza de la desigualdad económica y una caída del ingreso real de amplios sectores de la población. Al aumentar la inseguridad, las reacciones culturales contra el giro posmaterialista, que éste inspiró desde su inicio en grupos aferrados a valores tradicionales, han ganado intensidad con el ascenso electoral de partidos y candidatos xenófobos, misóginos y racistas.

Pero Inglehart (2018) acaba de mostrar, a partir de datos de la WVS, que las "normas de elección individual" (NEI) -que comprenden la igualdad de género y las nuevas normas familiares y sexuales de aceptación de la homosexualidad, el aborto y el divorcio- están avanzando en varias sociedades con gran rapidez, superior a la del solo reemplazo 
generacional. Jorge $(2011,2012)$ había comprobado este hecho en el caso de la aprobación de la homosexualidad en la Argentina.

Los hallazgos de Inglehart (ver Inglehart, Ponarin e Inglehart, 2017) explican un número de fenómenos, algunos aparentemente contradictorios, observables no solo en los países desarrollados, sino también, al menos en parte, en sociedades como la argentina.

Uno es que la creciente aprobación de las NEI promovida por el cambio generacional alcanzó un punto de inflexión en el que la opinión social prevaleciente pasó del rechazo a la aceptación de las nuevas normas. La presión social sobre los individuos viró entonces su polaridad. En lugar de inhibir, ahora estimula la aprobación de las NEI. Hemos asistido en nuestro país a varios casos resonantes de artistas y otras figuras públicas cuyas declaraciones misóginas $u$ homofóbicas han motivado el rechazo general.

Esta presión para la conformidad tiene empero efectos paradójicos. Algunos adaptan su conducta en ciertos contextos sociales para evitar la sanción informal, pero no adquieren actitudes más abiertas hacia las nuevas normas. Surgen actitudes ambivalentes y formas sutiles de prejuicio. Aún en heterosexuales que apoyan el matrimonio entre personas del mismo sexo se ha observado menos aceptación para "derechos informales" como la demostración pública de afecto (Doan, Loehr y Miller, 2014). En varones y mujeres heterosexuales suelen coexistir formas "benevolentes" y "hostiles" de sexismo (Glick y Fiske, 2011).

Otra hipótesis es que las actitudes - positivas o negativas- hacia los distintos componentes de las NEI se hallan estrechamente relacionadas entre sí. Pharr (1988) ha examinado la conexión entre machismo y homofobia. No es infrecuente que las mujeres agredidas por sus parejas masculinas sean calificadas por éstas de lesbianas. En síntesis, las personas que rechazan la igualdad de género también desaprueban la homosexualidad, el aborto y el divorcio; las que defienden la primera, aceptan las segundas.

Inglehart observa que las normas familiares y sexuales tradicionales han distinguido históricamente a las sociedades agrarias, donde la precariedad de la vida y la alta mortalidad infantil tendían a estimular "normas pro-fertilidad". Estas instigaban a la mujer a criar muchos hijos y ceder el liderazgo al varón, además de condenar toda conducta sexual no ligada a la reproducción.

Estas normas fueron inculcadas por las religiones de modo que su violación generara intensa culpa y temor. Profundamente arraigadas en la sociedad, cedieron al principio lentamente, aun cuando las circunstancias que las originaron ya habían cambiado. Inglehart presenta evidencia de que las NEI se han vuelto predominantes en los países industriales recién 40 ○ 50 años después de que se dieran las condiciones de "seguridad existencial" en que descansan. Más 
aún, su tesis es que el predictor más potente del grado de aceptación de las NEI en un país no es su nivel actual de seguridad existencial, sino el que prevalecía varias décadas atrás.

\section{Análisis empírico}

Mi primer paso es contrastar las hipótesis de Inglehart usando su propia estrategia de análisis. Reuní los datos necesarios para una muestra de 63 países encuestados por la WVS entre 2005 y 2014, con 2011 como año promedio (Tabla A del Anexo). Un análisis factorial de los seis indicadores de las NEI más extensamente relevados en el mundo (Tabla 1) muestra en efecto que, en el nivel de las sociedades, las actitudes hacia la igualdad de género -referidas el liderazgo, el trabajo y la educación superior- forman una misma dimensión con las vinculadas a las normas familiares y sexuales sobre homosexualidad, aborto y divorcio.

Al realizar un análisis factorial en el nivel de los individuos con los datos de la WVS para la Argentina en 2013 surgieron empero dos dimensiones distintas. Para este examen recodifiqué los indicadores de la Tabla 1 en escalas de 1 a 10, con justificación creciente de la homosexualidad, el aborto y el divorcio, y desacuerdo creciente sobre la preeminencia de los varones en el liderazgo, el empleo y la educación universitaria (Jorge, 2018a).

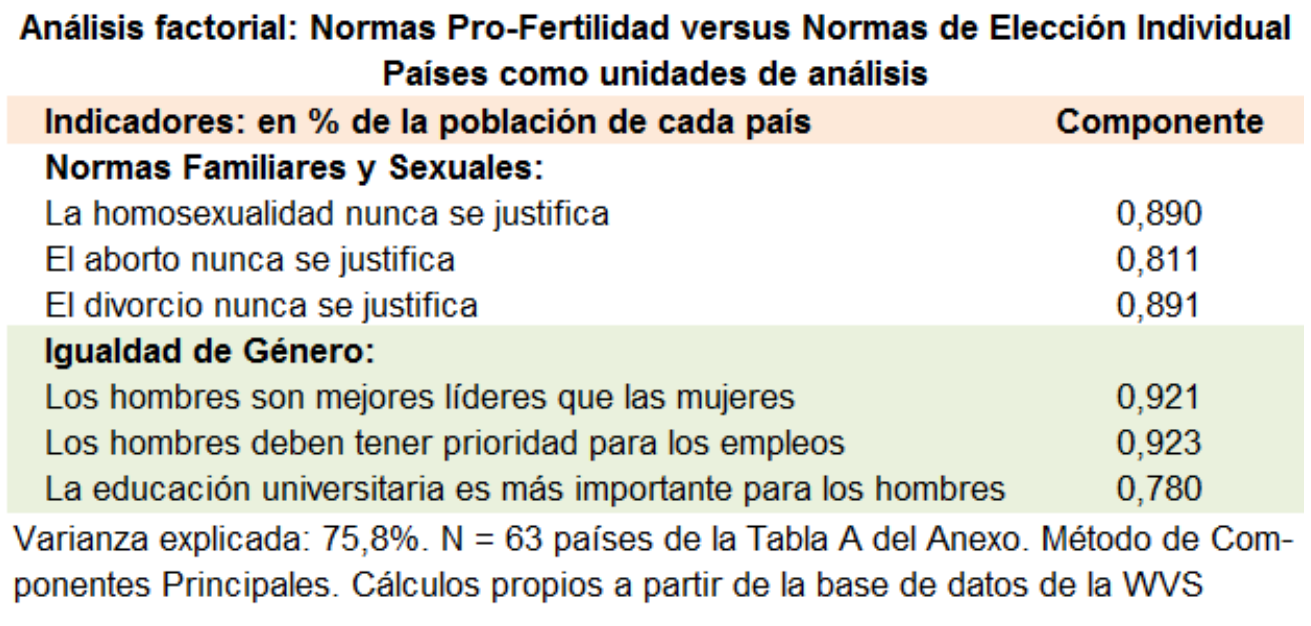

Tabla 1

De todos modos, el índice de igualdad de género predice de un modo significativo al que promedia los tres ítems de las normas familiares y sexuales, como se ve en las regresiones de la Tabla 2 (modelos 3 y 4). Aquí también son significativos dos predictores resaltados por Inglehart (2018): la religiosidad de las personas -medida por la importancia de Dios en la vida 
del encuestado-, que tiene un impacto negativo, y el posmaterialismo con un efecto positivo. Este último índice computa el número de cuestiones posmaterialistas - de 0 a 5 - que los argentinos eligen como prioridades de un total de 12 que se les presentan. Incluye (por encima de temas materialistas como la inflación, el crecimiento económico y la lucha contra el delito, entre otros) la libertad de expresión, la participación de los ciudadanos en las decisiones de gobierno, tener en cuenta la opinión de la gente en el trabajo y la comunidad y una sociedad donde las ideas importen más que el dinero.

Argentina 2013. Normas familiares y sexuales (indice de 3 items)

\begin{tabular}{|c|c|c|c|c|}
\hline \multicolumn{5}{|c|}{ Justificacion de la homosexualidad, el aborto y el divorcio } \\
\hline $\begin{array}{l}\text { Análisis de } \\
\text { regresión lineal }\end{array}$ & 1 & 2 & 3 & 4 \\
\hline Edad & $\begin{array}{l}-0,014 * * \\
(-2,973\end{array}$ & $\begin{array}{l}-0,010 * \\
(-2,176)\end{array}$ & $\begin{array}{l}-0,009 \text { * } \\
(-1,998)\end{array}$ & $\begin{array}{l}-0,008+ \\
(-1,696)\end{array}$ \\
\hline $\begin{array}{l}\text { Educación: universitaria } \\
\text { completa o incompleta }\end{array}$ & $\begin{array}{l}1,183^{\star \star \star} \\
(4.870)\end{array}$ & $\begin{array}{l}0,677^{* *} \\
(2,744)\end{array}$ & $\begin{array}{c}0,432+ \\
(1,741)\end{array}$ & $\begin{array}{l}0,090 \text { ns } \\
(0,333)\end{array}$ \\
\hline $\begin{array}{l}\text { Educación: media } \\
\text { completa }\end{array}$ & $\begin{array}{c}0,347+ \\
(1,933)\end{array}$ & $\begin{array}{l}0,275 \mathrm{~ns} \\
(1,535)\end{array}$ & $\begin{array}{l}0,212 \mathrm{~ns} \\
(1,187)\end{array}$ & $\begin{array}{l}0,084 \mathrm{~ns} \\
(0,439)\end{array}$ \\
\hline Género: mujer & $\begin{array}{l}-0,055 \mathrm{~ns} \\
(-0,344)\end{array}$ & $\begin{array}{l}-0,036 \text { ns } \\
(-0.226)\end{array}$ & $\begin{array}{l}-0,198 \text { ns } \\
(-1,223)\end{array}$ & $\begin{array}{l}0,011 \mathrm{~ns} \\
(0,061)\end{array}$ \\
\hline Nivel de Ingreso & $\begin{array}{l}-0,012 \text { ns } \\
(-0.227)\end{array}$ & $\begin{array}{c}0,004 \mathrm{~ns} \\
(0,083)\end{array}$ & $\begin{array}{l}0,022 \text { ns } \\
(0,417)\end{array}$ & $\begin{array}{l}0,072 \text { ns } \\
(1,264)\end{array}$ \\
\hline $\begin{array}{l}\text { Posmaterialismo: indice } \\
\text { de } 12 \text { items }\end{array}$ & & $\begin{array}{c}0,292 \text { *** } \\
(4,015)\end{array}$ & $\begin{array}{l}0,261 \text { *** } \\
(3,616)\end{array}$ & $\begin{array}{l}0,208 \text { ** } \\
(2,640)\end{array}$ \\
\hline $\begin{array}{l}\text { Religiosidad: importancia } \\
\text { de Dios en nuestra vida }\end{array}$ & & $\begin{array}{l}-0,190^{* \star *} \\
(-5,747)\end{array}$ & $\begin{array}{l}-0,204^{* * *} \\
(-6,225)\end{array}$ & $\begin{array}{l}-0,223^{\text {*** }} \\
(-6,168)\end{array}$ \\
\hline $\begin{array}{l}\text { Igualdad de Género: } \\
\text { Índice de } 3 \text { items }\end{array}$ & & & $\begin{array}{c}0,185^{* \star \star} \\
(5,395)\end{array}$ & $\begin{array}{l}0,159 \text { *** } \\
(4,198)\end{array}$ \\
\hline $\begin{array}{l}\text { Confianza en el } \\
\text { Exogrupo }\end{array}$ & & & & $\begin{array}{l}0,838 * \\
(2,292)\end{array}$ \\
\hline Demócrata Sólido & & & & $\begin{array}{l}0,556 \text { ** } \\
(3,137)\end{array}$ \\
\hline $\begin{array}{l}\mathrm{N}^{0} \text { de medios utilizados } \\
\text { para informarse }\end{array}$ & & & & $\begin{array}{l}0,134 \text { ** } \\
(2,809)\end{array}$ \\
\hline Constante & $\begin{array}{r}5,695^{* \star \star} \\
(14.622)\end{array}$ & $\begin{array}{r}6,361 \\
(13,344)\end{array}$ & $\begin{array}{l}5,240 \text { *** } \\
(10,217)\end{array}$ & $\begin{array}{l}4,005^{\text {*** }} \\
(6,745)\end{array}$ \\
\hline $\mathrm{R}^{2}$ Ajustada & 0,04 & 0,09 & 0,12 & 0,16 \\
\hline $\mathrm{N}^{0}$ de Casos & 852 & 797 & 786 & 664 \\
\hline
\end{tabular}

Fuente: Cálculos propios a partir de la base de datos WVS Argentina 2013. Las entradas son coeficientes de regresión no tipificados (valores t entre paréntesis). Variable dependiente: Promedio de las escalas de justificación del aborto, la homosexualidad y el divorcio. Escala 1-10. Variables Independientes. Nivel de ingreso: En deciles. Escala 1-10. Posmaterialismo: Escala 0-5. Religiosidad: Escala 1-10. Igualdad de género. Escala 110. Promedio de 3 items (liderazgo, empleo y educación superior). Confianza en el exogrupo: Escala 0-1 (Jorge, 2016a). Demócrata sólido: Variable dummy (Jorge, 2015: 379). $\mathbf{N}^{0}$ de medios: Escala $0-8{ }^{* *} p<0.001{ }^{* *} p<0.01{ }^{*} p<0.05+p<0.1$ ns: no significativo

Tabla 2 
El modelo 4 de la Tabla 2 muestra que las nuevas normas familiares y sexuales están positivamente asociadas con la confianza en el exogrupo, que mide el grado en que los argentinos confían en los desconocidos y en las personas de otra religión y otra nacionalidad (Jorge, 2016a: 152). Surge la misma relación entre esas normas y los "demócratas sólidos", una medida fuerte de apoyo a la democracia que combina actitudes de adhesión al sistema con otras de rechazo a alternativas autoritarias (Jorge, 2015: 379). En igual dirección opera el influjo de la cantidad de medios que los entrevistados usan para informarse, un indicador de "movilización cognoscitiva" (Jorge, 2010: 91).

¿Depende la actual aceptación de las NEI en un país de sus condiciones de vida en el pasado, más que de las presentes? A fin de extender mi análisis, en la medida de lo posible, a los países de América Latina no cubiertos por la WVS, incorporé los datos relevados por Latinobarómetro en 18 sociedades de la región sobre dos de los seis ítems de las NEI: la justificación del aborto (en 2015) y el desacuerdo con que los hombres son mejores líderes que las mujeres (en 2009) (Tabla B del Anexo). Para estos dos indicadores, nuestro examen se amplía de las 63 naciones de la WVS (9 de ellas latinoamericanas) a 72-18 de nuestra regiónreuniendo los datos de ambas encuestas.

Siguiendo la estrategia de análisis de Inglehart, calculé para todos estos países un Índice de Seguridad Existencial (ISE) cada diez años, desde 1970 hasta 2010. Esta medida combina el ingreso por habitante -estimado por el Institute for Health Metrics and Evaluation (James, Gubbins, Murray y Gakidou, 2012)-, la esperanza de vida al nacer y la tasa de mortalidad infantil. Las tablas del Anexo incluyen los datos de 1970 y sus detalles técnicos. Los valores del ISE son las puntuaciones de un análisis factorial, del que surge una sola dimensión para los tres indicadores. 


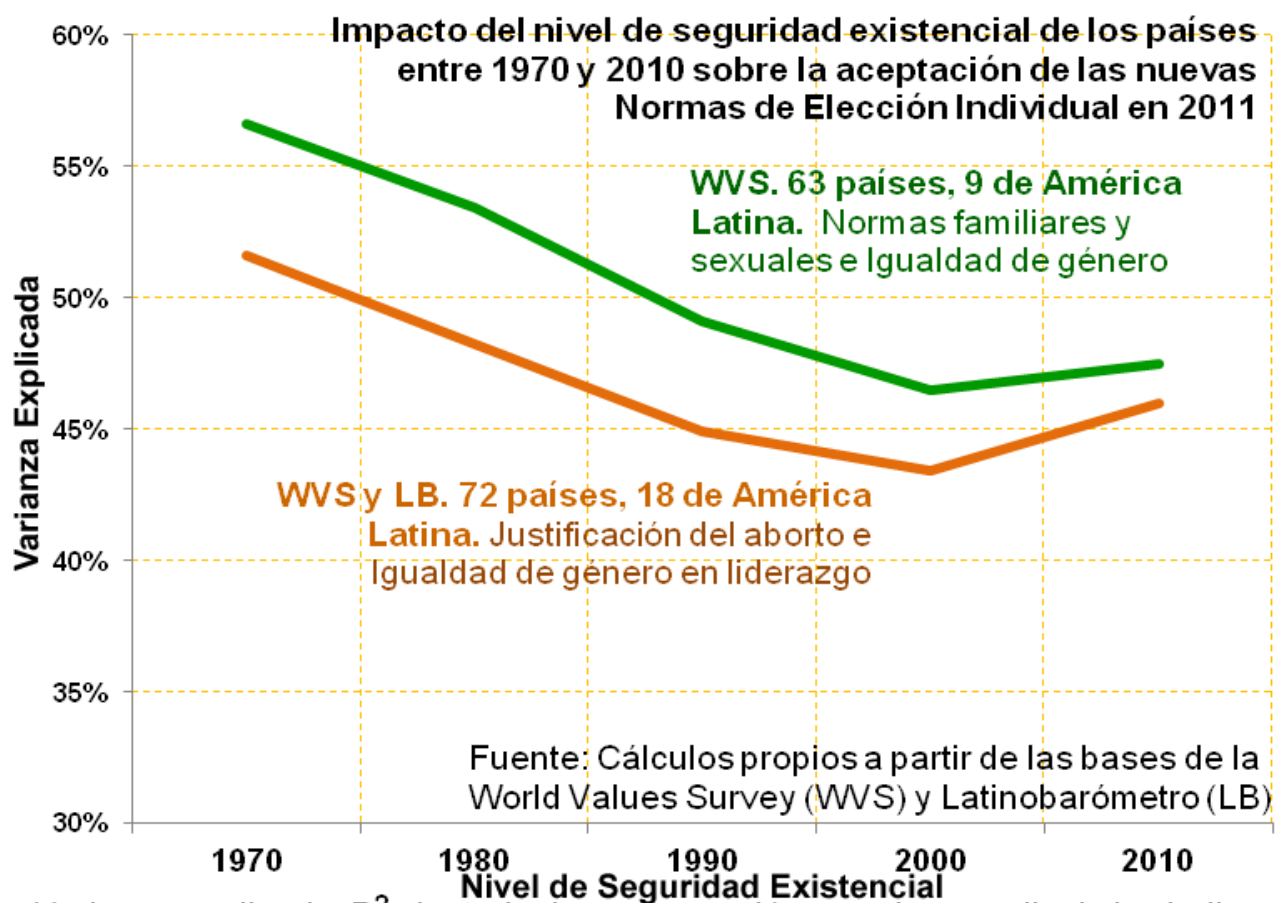

Varianza explicada: $\mathrm{R}^{2}$ ajustada de una regresión con el promedio de los indicadores de las NEI como variable dependiente y el índice ISE como independiente

Figura 1

Los resultados de nuestro escrutinio apoyan las hipótesis de partida. En la Figura 1, el nivel de seguridad existencial en 1970 es el predictor más potente de las NEI alrededor de 2011. Las NEI se calculan como la media de los seis ítems en la base de 63 países (Tabla A del Anexo) y de los dos ítems comunes a los 72 países de la base ampliada. En este último caso se usa el dato más reciente de ambas encuestas y el año promedio es también 2011. Surgen las mismas conclusiones si predecimos una medida de las NEI limitada a las normas familiares y sexuales (Figura 2).

Los tres gráficos que siguen permiten apreciar la posición de las 18 sociedades relevadas por Latinobarómetro en perspectiva comparada internacional. La Figura 1 ilustra la correlación entre el ISE 1970 de cada país -medido por sus puntuaciones factoriales- y la escala media de justificación del aborto e igualdad de género en liderazgo alrededor de 2011. 


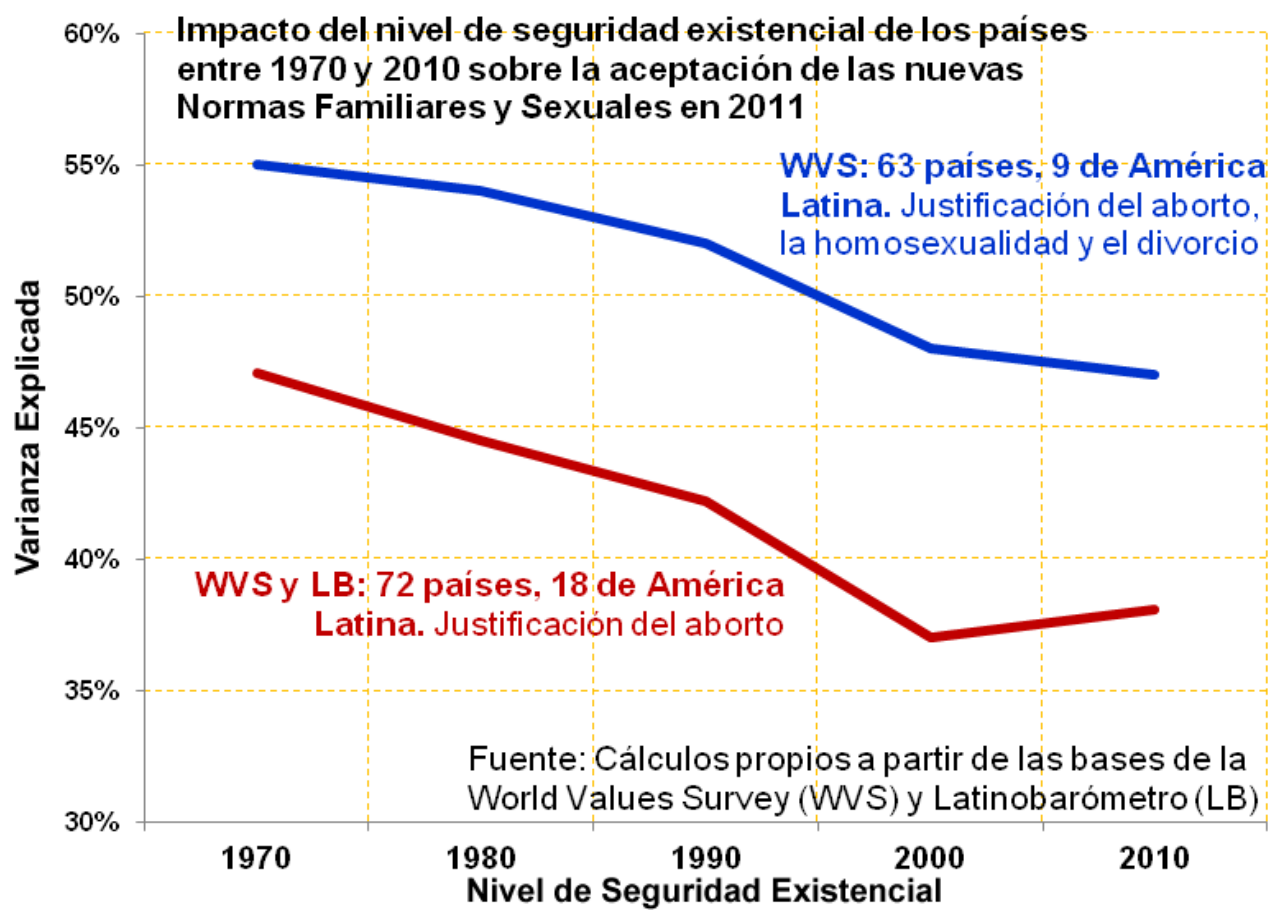

Figura 2

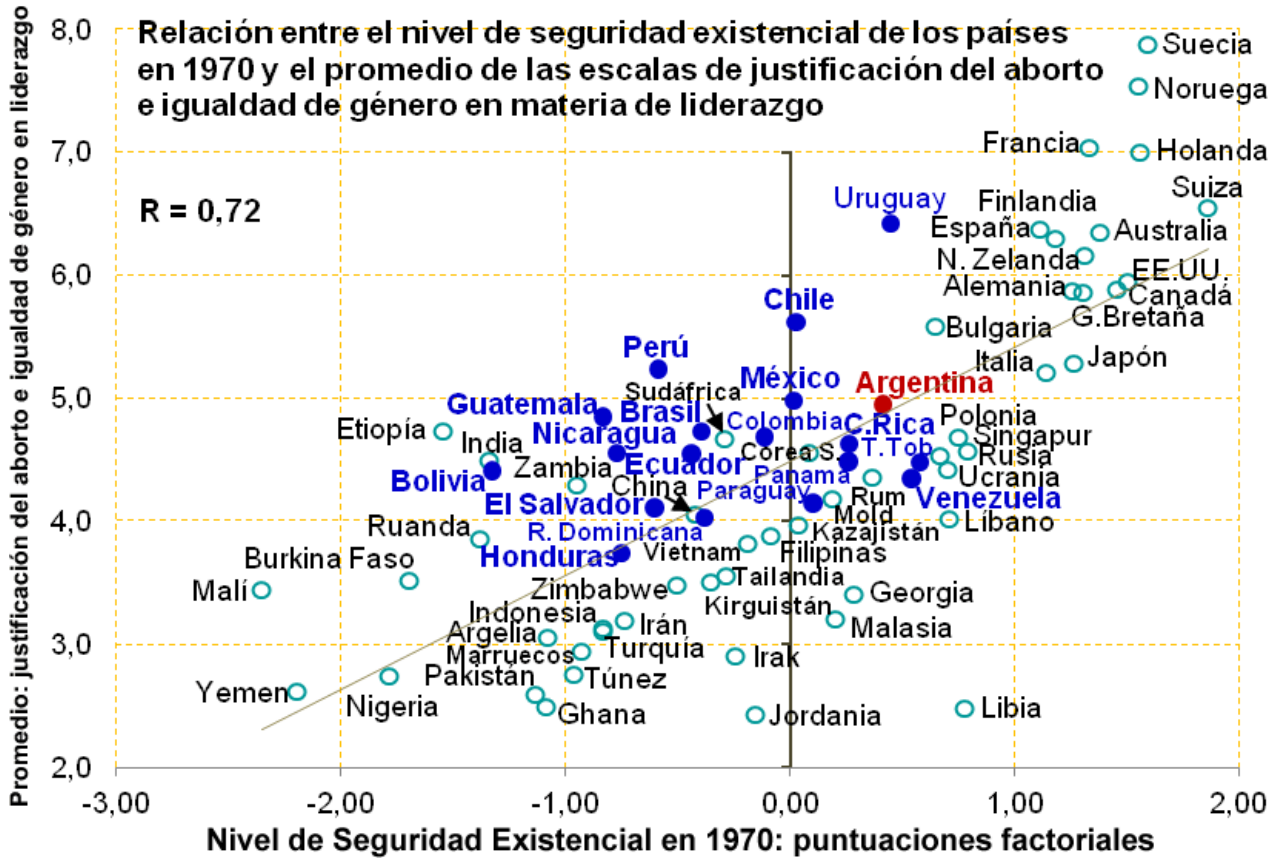

Figura 3 
Nuestra medida de dos ítems de las NEI tiene además una fuerte correlación negativa con el Índice de Desigualdad de Género del Programa de las Naciones Unidas para el Desarrollo (PNUD) (Figura 4). Este último varía entre 0 y 1 y aumenta con la desigualdad. Mide las inequidades en salud (mortalidad materna y madres adolescentes), educación secundaria, representación parlamentaria y participación laboral.

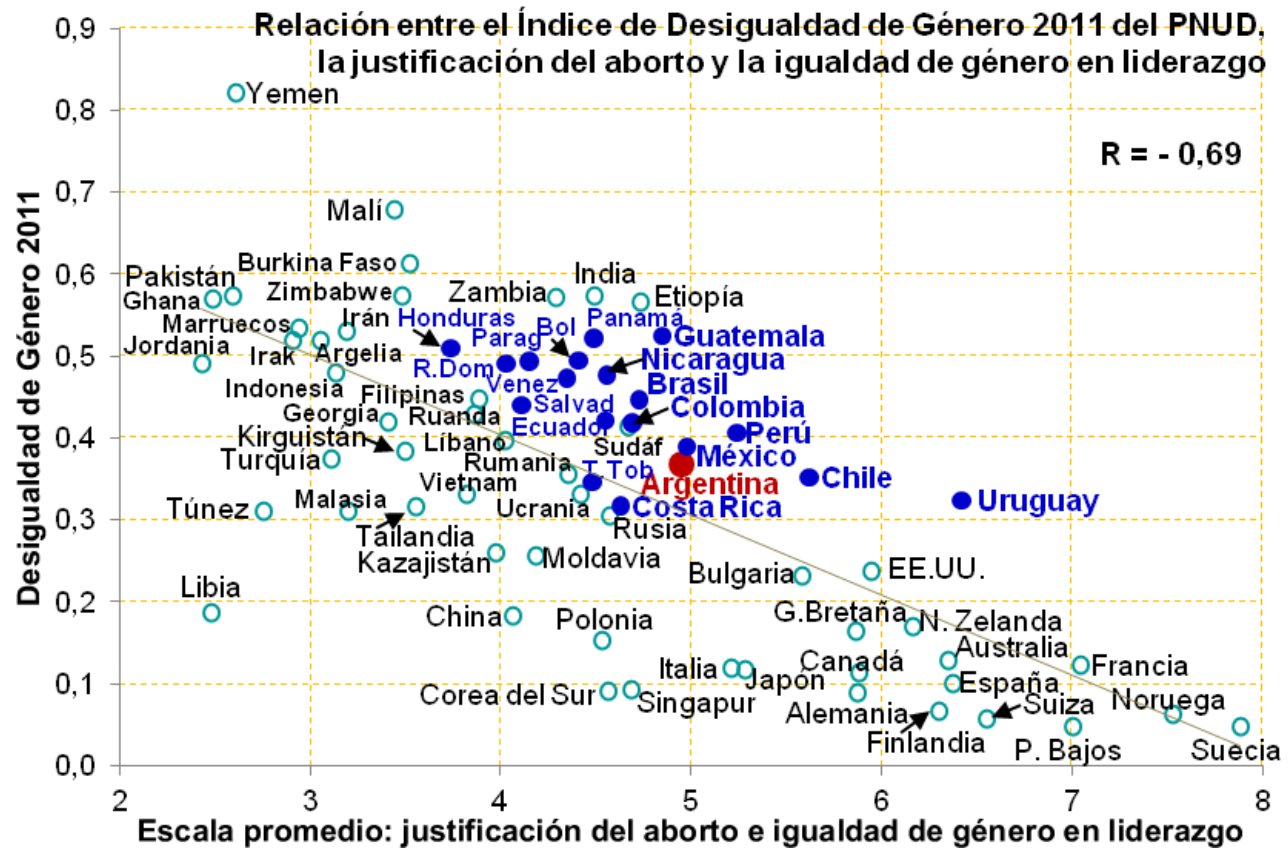

Figura 4 


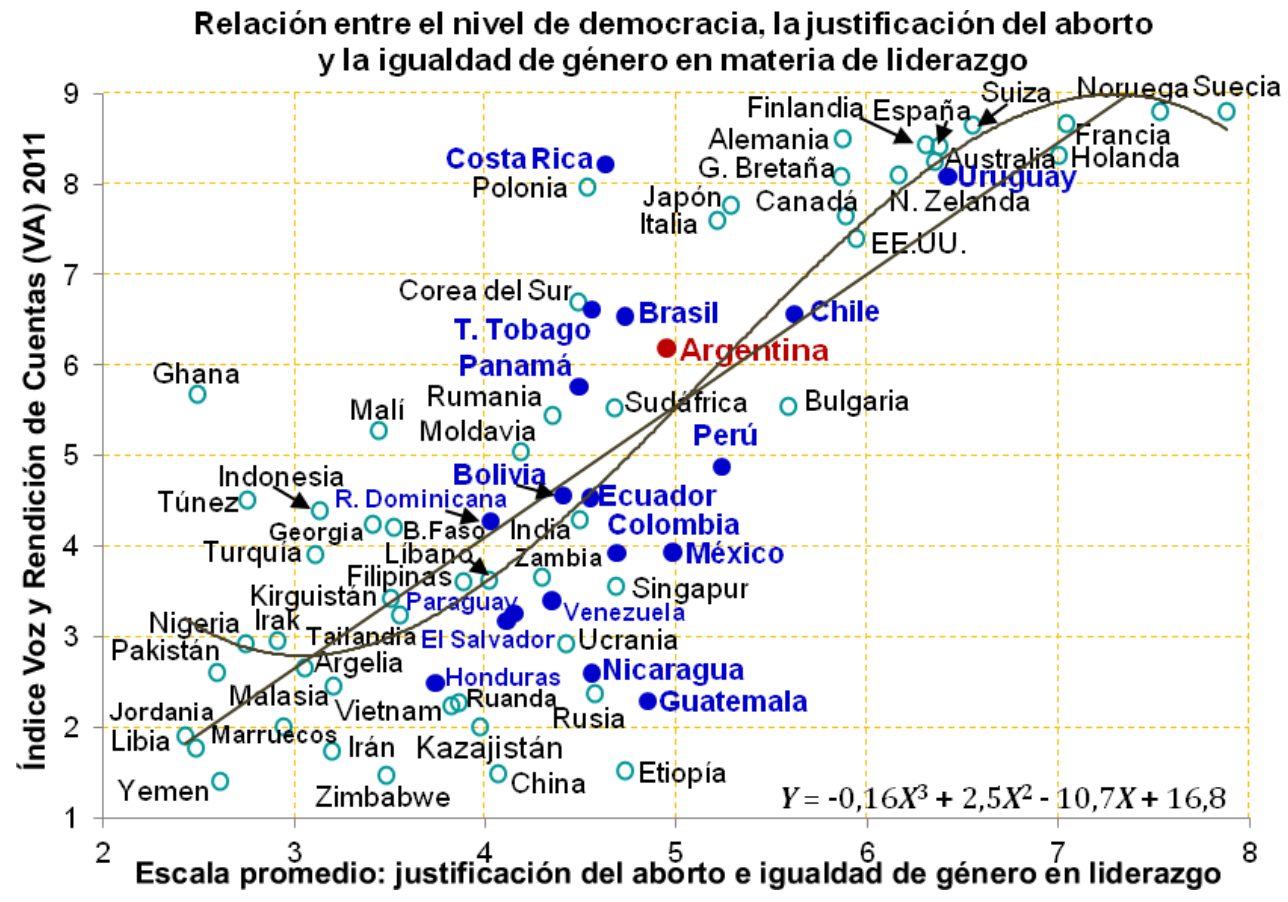

Figura 5

La Figura 5 refleja la elevada correlación entre el mismo indicador de las NEI y el nivel de democracia según el índice Voz y Rendición de Cuentas del Banco Mundial (Jorge, 2018b). Ha sido observado reiteradamente que estas normas, al encarnar con tanta fuerza los valores de libertad de elección e igualdad de oportunidades, predicen el nivel de democracia mucho mejor que los indicadores de "apoyo" declarado al sistema, que suelen esconder concepciones disímiles -incluso autoritarias- de la democracia (Inglehart, 2016; Jorge, 2018b). 
Variable dependiente: Normas de Elección Individual (6 items) Normas familiares y sexuales e Igualdad de género

\begin{tabular}{|c|c|c|c|c|}
\hline $\begin{array}{l}\text { Análisis de } \\
\text { regresión lineal }\end{array}$ & 1 & 2 & 3 & 4 \\
\hline Índice de Seguridad & $4,369 * * *$ & $3,130 * \star \star$ & 2,315 *** & $2,417^{\star \star * *}$ \\
\hline Existencial en 1970 & $(9,050)$ & $(6,391)$ & $(4,376)$ & $(4,901)$ \\
\hline $\begin{array}{l}\text { Índice de Posmaterialis- } \\
\text { mo de Inglehart: } 12 \text { items }\end{array}$ & & $\begin{array}{l}1,415^{* \star *} \\
(4,759)\end{array}$ & $\begin{array}{l}1,299 * * * \\
(4,627)\end{array}$ & $\begin{array}{l}1,267^{* * *} \\
(4,591)\end{array}$ \\
\hline $\begin{array}{l}\text { Religiosidad: importan- } \\
\text { cia de Dios en la vida }\end{array}$ & & & $\begin{array}{c}-0,192 \text { ** } \\
(-3,086)\end{array}$ & \\
\hline $\begin{array}{l}\text { Índice de Valores Secu- } \\
\text { lares de Welzel }\end{array}$ & & & & $\begin{array}{l}5,127^{* \star *} \\
(3,504)\end{array}$ \\
\hline Constante & $\begin{array}{l}2,548^{* * \star} \\
(8,526)\end{array}$ & $\begin{array}{l}0,427 \mathrm{~ns} \\
(0,831)\end{array}$ & $\begin{array}{l}2,599 * * \\
(3,048)\end{array}$ & $\begin{array}{l}-0,697 \text { ns } \\
(-1,222)\end{array}$ \\
\hline $\mathbf{R}^{2}$ Ajustada & 0,57 & 0,68 & 0,72 & 0,73 \\
\hline $\mathrm{N}^{0}$ de Casos & 63 países & 63 países & 63 países & 63 países \\
\hline \multicolumn{5}{|c|}{$\begin{array}{l}\text { Variable dependiente: Normas de Elección Individual ( } 3 \text { items) } \\
\text { Justificación del aborto, la homosexualidad y el divorcio }\end{array}$} \\
\hline $\begin{array}{l}\text { Variables } \\
\text { Independientes }\end{array}$ & 1 & 2 & 3 & 4 \\
\hline $\begin{array}{l}\text { Índice de Seguridad } \\
\text { Existencial en } 1970\end{array}$ & $\begin{array}{l}4,934 * * * \\
(8,827)\end{array}$ & $\begin{array}{l}3,683^{* * *} \\
(6,220)\end{array}$ & $\begin{array}{l}2,430 * * * \\
(4,004)\end{array}$ & $\begin{array}{l}2,671 \text { *** } \\
(4,667)\end{array}$ \\
\hline $\begin{array}{l}\text { Îndice de Posmaterialis- } \\
\text { mo de Inglehart: } 12 \text { items }\end{array}$ & & $\begin{array}{l}1,428^{* \star \star} \\
(3,972)\end{array}$ & $\begin{array}{c}1,249 \text { *** } \\
(3,879)\end{array}$ & $\begin{array}{l}1,217^{\star \star \star *} \\
(3,802)\end{array}$ \\
\hline $\begin{array}{l}\text { Religiosidad: importan- } \\
\text { cia de Dios en la vida }\end{array}$ & & & 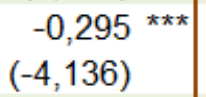 & \\
\hline $\begin{array}{l}\text { Índice de Valores Secu- } \\
\text { lares de Welzel }\end{array}$ & & & & $\begin{array}{l}7,285^{\text {***}} \\
(4,292)\end{array}$ \\
\hline Constante & $\begin{array}{l}1,081 \text { ** } \\
(3,125)\end{array}$ & $\begin{array}{c}-1,058+ \\
(-1,702)\end{array}$ & $\begin{array}{l}2,282 * \\
(2,333)\end{array}$ & $\begin{array}{l}-2,656 \text { *** } \\
(-4,013)\end{array}$ \\
\hline $\begin{array}{l}\mathbf{R}^{2} \text { Ajustada } \\
\mathbf{N}^{0} \text { de Casos }\end{array}$ & $\begin{array}{c}\mathbf{0 , 5 5} \\
63 \text { países }\end{array}$ & $\begin{array}{c}\mathbf{0 , 6 4} \\
63 \text { países }\end{array}$ & $\begin{array}{c}0,72 \\
63 \text { países }\end{array}$ & $\begin{array}{c}\mathbf{0 , 7 2} \\
63 \text { países }\end{array}$ \\
\hline
\end{tabular}

Fuente: Cálculos propios. Las entradas son coeficientes de regresión no tipificados (valores t entre paréntesis) ${ }^{* * *} p<0.001{ }^{* *} p<0.01{ }^{*} p<0.05+p<0.1$ ns: no significativo

Tabla 3

Las regresiones de la Tabla 3 predicen las NEI de seis y tres ítems para los 63 países con todos los datos necesarios de la WVS. En el cuadro superior, el ISE 1970 explica por sí solo, como en la Figura 1, el 57\% de la varianza. Incorporar el índice de posmaterialismo eleva la $\mathrm{R}^{2}$ ajustada a 0,68 y añadir la religiosidad (cuyo efecto es negativo) la sube a 0,72. Sustituir a la segunda por un índice comprensivo de valores seculares (Welzel, 2013: 63-70; Jorge, 2018a: 14) aumenta la $R^{2}$ un punto adicional. 
Las regresiones que siguen predicen las políticas nacionales sobre violencia contra la mujer e interrupción voluntaria del embarazo examinando el impacto de los factores considerados hasta aquí.

\begin{tabular}{|c|c|c|c|c|c|c|c|}
\hline \multicolumn{8}{|c|}{ Variable dependiente: Políticas Nacionales en Respuesta a la Violencia Contra la Mujer } \\
\hline $\begin{array}{l}\text { Análisis de } \\
\text { regresión lineal }\end{array}$ & 1 & 2 & 3 & 4 & 5 & 6 & 7 \\
\hline \multicolumn{8}{|l|}{ Movimiento feminista } \\
\hline Fuerte y autónomo (MFA) & $\begin{array}{l}3,901 \\
(4,529)\end{array}$ & $\begin{array}{l}3,540 \text { *** } \\
(4,369)\end{array}$ & $\begin{array}{l}2,588 \text { *** } \\
(4,274)\end{array}$ & $\begin{array}{c}2,671 \text { *** } \\
(4,045)\end{array}$ & $\begin{array}{c}2,083^{\star \star \star} \\
(3,438)\end{array}$ & $\begin{array}{l}2,093 \\
(3,551)\end{array}$ & $\begin{array}{l}2,284 \\
(3,995)\end{array}$ \\
\hline $\begin{array}{l}\text { Moderadamente fuerte } \\
\text { y autónomo (MMFA) }\end{array}$ & $\begin{array}{l}3,274^{\star \star \star} \\
(3,678)\end{array}$ & $\begin{array}{l}3,337^{\star \star *} \\
(4,037)\end{array}$ & $\begin{array}{l}3,176 \text { *** } \\
(5,331)\end{array}$ & $\begin{array}{c}3,163^{* * *} \\
(5,221)\end{array}$ & $\begin{array}{c}2,781 \text { *** } \\
(4,757)\end{array}$ & $\begin{array}{l}2,566^{* \star *} \\
(4,358)\end{array}$ & $\begin{array}{l}2,4399^{* \star *} \\
(4,132)\end{array}$ \\
\hline \multicolumn{8}{|c|}{ Poder político de la mujer } \\
\hline $\begin{array}{l}\text { Mujeres en el Parlamento } \\
\% \text { de las bancas, } 2017\end{array}$ & & $\begin{array}{l}0,084 \text { ** } \\
(2,754)\end{array}$ & $\begin{array}{l}-0,007 \mathrm{~ns} \\
(-0,254)\end{array}$ & & & & \\
\hline \multicolumn{8}{|l|}{ Normas y Valores } \\
\hline $\begin{array}{l}\text { Igualdad de Género } \\
\text { (Tres items) }\end{array}$ & & & $\begin{array}{c}0,591^{\star} \\
(2,327)\end{array}$ & $\begin{array}{c}0,6222^{*} \\
(2,247)\end{array}$ & $\begin{array}{l}0,653^{\text {** }} \\
(2,577)\end{array}$ & $\begin{array}{c}0,465 \dagger \\
(1,661)\end{array}$ & \\
\hline $\begin{array}{l}\text { Posmaterialismo } \\
\text { Índice de } 12 \text { ítems }\end{array}$ & & & $\begin{array}{l}3,122 \text { *** } \\
(4,025)\end{array}$ & $\begin{array}{c}3,106^{* \star *} \\
(3,870)\end{array}$ & $\begin{array}{c}1,963^{*} \\
(2,272)\end{array}$ & $\begin{array}{r}1,561 \dagger \\
(1,742)\end{array}$ & $\begin{array}{c}1,590 \dagger \\
(1,792)\end{array}$ \\
\hline \multicolumn{8}{|l|}{ Interacción } \\
\hline $\begin{array}{l}\text { MFA x Igualdad } \\
\text { de Género }\end{array}$ & & & & $\begin{array}{c}-0,182 \mathrm{~ns} \\
(-0,398)\end{array}$ & & & \\
\hline $\begin{array}{l}\text { MMFA x Igualdad } \\
\text { de Género }\end{array}$ & & & & $\begin{array}{l}-0,117 \mathrm{~ns} \\
(-0,256)\end{array}$ & & & \\
\hline \multicolumn{8}{|l|}{ Sistema politico } \\
\hline Legado socialista & & & & & $\begin{array}{l}-1,657 * \\
(-2,292)\end{array}$ & $\begin{array}{l}-1,523 * \\
(-2,138)\end{array}$ & $\begin{array}{l}-1,793 * \\
(-2,319)\end{array}$ \\
\hline $\begin{array}{l}\text { Nivel de Democracia } \\
\text { Índice VAI } 2005\end{array}$ & & & & & & $\begin{array}{l}2,603 \text { ns } \\
(1,465)\end{array}$ & $\begin{array}{c}3,073 \dagger \\
(1,941)\end{array}$ \\
\hline \multicolumn{8}{|l|}{ Religiosidad } \\
\hline $\begin{array}{l}\text { Religión Islámica } \\
\text { predominante }\end{array}$ & & & & & & & $\begin{array}{l}-1,299 \dagger \\
(-1,743)\end{array}$ \\
\hline \multicolumn{8}{|l|}{ Ingreso por habitante } \\
\hline $\begin{array}{l}\text { U\$S int. ctes 2011, PPA } \\
\text { (logaritmo natural) }\end{array}$ & & & & & $\begin{array}{c}0,239 \mathrm{~ns} \\
(0,594)\end{array}$ & & \\
\hline Constante & 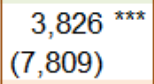 & $\begin{array}{r}2,338 \text { ** } \\
(3,311)\end{array}$ & $\begin{array}{l}-6,032^{\text {** }} \\
(-4,279)\end{array}$ & $\begin{array}{l}-2,314 \mathrm{~ns} \\
(-1,341)\end{array}$ & $\begin{array}{c}-5,940 \dagger \\
(-1,858)\end{array}$ & $\begin{array}{l}-3,228 \text { * } \\
(-2,039)\end{array}$ & $\begin{array}{l}-0,250 \mathrm{~ns} \\
(-0,131)\end{array}$ \\
\hline $\mathbf{R}^{2}$ ajustada & 0,36 & 0,45 & 0,72 & 0,71 & 0,75 & 0,76 & 0,76 \\
\hline $\mathrm{N}^{0}$ de Casos & 44 países & 44 países & 44 países & 44 países & 44 países & 44 países & 44 países \\
\hline
\end{tabular}

Fuente: cálculos propios.Las entradas son coeficientes de regresión no tipificados (valores t entre paréntesis).

Variable dependiente: Politicas Nacionales en Respuesta a la Violencia contra la Mujer. Escala 0-10. Año 2005. (Htun y Weldon, 2012, 2018). Movimiento feminista fuerte y autónomo: variables dummy. Año 2005 (Htun y Weldon, 2012, 2018). Mujeres en el Parlamento. Unión Interparlamentaria (IPU), 2016. Religión predominante: variable dummy (Alesina et al., 2003)..Legado socialista: variable dummy. Ingreso p/hab. Banco Mundial:. ${ }^{* * *} \mathrm{p}<0.001{ }^{* *} \mathrm{p}<0.01{ }^{*} \mathrm{p}<0.05+\mathrm{p}<0.1$ ns: no significativo

Tabla 4

En la Tabla 4, la variable a predecir es un índice elaborado por Htun y Weldon $(2012,2018)$ que mide la respuesta de los gobiernos a la violencia contra la mujer. Obtienen puntajes más altos los países que adoptan un gran abanico de políticas: reformas legales y administrativas, 
servicios a las víctimas, acciones de prevención, programas para grupos vulnerables y capacitación profesional. Utilizo los valores del índice en 2005, el último disponible. El número de casos está limitado a los 44 países de nuestra lista con datos sobre movilización feminista en la sociedad civil.

\begin{tabular}{|c|c|c|c|c|c|c|c|}
\hline \multicolumn{8}{|c|}{ Variable Dependiente: Aborto Ampliamente Legal } \\
\hline $\begin{array}{l}\text { Análisis de } \\
\text { regresión logística }\end{array}$ & 1 & 2 & 3 & 4 & 5 & 6 & 7 \\
\hline \multicolumn{8}{|l|}{ Movimiento feminista } \\
\hline Fuerte y autónomo (MFA) & $\begin{array}{l}-0,167 \mathrm{~ns} \\
(0.708)\end{array}$ & & $\begin{array}{l}-0,618 \mathrm{~ns} \\
(0.808)\end{array}$ & & & & \\
\hline $\begin{array}{l}\text { Moderadamente fuerte } \\
\text { y autónomo (MMFA) }\end{array}$ & $\begin{array}{c}0,238 \mathrm{~ns} \\
(0.765)\end{array}$ & & $\begin{array}{l}-0,019 \mathrm{~ns} \\
(0.808)\end{array}$ & & & & \\
\hline \multicolumn{8}{|c|}{ Poder político de la mujer } \\
\hline $\begin{array}{l}\text { Mujeres en el Parlamento } \\
\% \text { de las bancas, } 2017\end{array}$ & & $\begin{array}{l}0,019 \mathrm{~ns} \\
(0,020)\end{array}$ & $\begin{array}{l}0,102 \text { * } \\
(0,051)\end{array}$ & & & & \\
\hline \multicolumn{8}{|l|}{ Interacción } \\
\hline $\begin{array}{l}\text { MFA X Mujeres en } \\
\text { el Parlamento }\end{array}$ & & & $\begin{array}{l}-0,056 \mathrm{~ns} \\
(0,077)\end{array}$ & & & & \\
\hline $\begin{array}{l}\text { MMFA X Mujeres en } \\
\text { el Parlamento }\end{array}$ & & & $\begin{array}{l}-0,102 \text { ns } \\
(0,085)\end{array}$ & & & & \\
\hline \multicolumn{8}{|l|}{ Religiosidad } \\
\hline $\begin{array}{l}\text { Importancia de Dios en } \\
\text { la vida del entrevistado }\end{array}$ & & & & $\begin{array}{l}-0,427 \dagger \\
(0,245)\end{array}$ & $\begin{array}{l}-0,498 * \\
(0,241)\end{array}$ & $\begin{array}{l}-0,015 \mathrm{~ns} \\
(0,325)\end{array}$ & \\
\hline $\begin{array}{l}\text { Religión Católica } \\
\text { predominante }\end{array}$ & & & & $\begin{array}{l}-2,1022^{*} \\
(1,082)\end{array}$ & $\begin{array}{l}-1,756 \dagger \\
(1,060)\end{array}$ & $\begin{array}{l}-1,571 \mathrm{~ns} \\
(1,083)\end{array}$ & $\begin{array}{l}-2,294 * \\
(1,039)\end{array}$ \\
\hline \multicolumn{8}{|l|}{ Sistema político } \\
\hline Legado socialista & & & & $\begin{array}{r}2,400 \dagger \\
(1,303)\end{array}$ & $\begin{array}{r}3,031 * \\
(1,225)\end{array}$ & $\begin{array}{c}3,194 * \\
(1,296)\end{array}$ & $\begin{array}{l}3,405^{* *} \\
(1,209)\end{array}$ \\
\hline $\begin{array}{l}\text { Nivel de Democracia } \\
\text { Índice VAl } 2016\end{array}$ & & & & $\begin{array}{c}0,443 \dagger \\
(0,241)\end{array}$ & $\begin{array}{c}0,514 \text { * } \\
(0,248)\end{array}$ & $\begin{array}{c}0,144 \mathrm{~ns} \\
(0,289)\end{array}$ & $\begin{array}{c}0,160 \mathrm{~ns} \\
(0,290)\end{array}$ \\
\hline \multicolumn{8}{|l|}{ Influencia de los médicos } \\
\hline Médicos $\mathrm{c} / 1.000$ hab. & & & & $\begin{array}{l}0,589 \text { ns } \\
(0,439)\end{array}$ & & & \\
\hline \multicolumn{8}{|l|}{ Normas de Elección Indiv. } \\
\hline $\begin{array}{l}\text { Igualdad de Género } \\
\text { (Tres items) }\end{array}$ & & & & & $\begin{array}{c}0,138 \mathrm{~ns} \\
(0,441)\end{array}$ & & \\
\hline $\begin{array}{l}\text { Justificación del Aborto } \\
\text { (Escala 1-10) }\end{array}$ & & & & & & $\begin{array}{c}1,535 * \\
(0,685)\end{array}$ & $\begin{array}{l}1,606^{\star *} \\
(0,547)\end{array}$ \\
\hline \multicolumn{8}{|l|}{ Ingreso por habitante } \\
\hline $\begin{array}{l}\text { U\$S int. ctes 2011, PPA } \\
\text { (logaritmo natural) }\end{array}$ & & & & $\begin{array}{l}-0,002 \text { ns } \\
(0,583)\end{array}$ & & & \\
\hline Constante & $\begin{array}{c}0,167 \text { ns } \\
(0,410)\end{array}$ & $\begin{array}{l}-0,757 \mathrm{~ns} \\
(0,544)\end{array}$ & $\begin{array}{l}0,425 \mathrm{~ns} \\
(0,485)\end{array}$ & {$\left[\begin{array}{l}-0,277 \mathrm{~ns} \\
(6,123)\end{array}\right.$} & $\begin{array}{l}-0,039 \text { ns } \\
(3,572)\end{array}$ & $\mid \begin{array}{l}-5,803 \mathrm{~ns} \\
(4,020)\end{array}$ & $\begin{array}{l}-6,246^{* * *} \\
(1,535)\end{array}$ \\
\hline $\begin{array}{l}\text { Pseudo } R^{2} \text { Cox y Snell } \\
\mathrm{N}^{0} \text { de Casos }\end{array}$ & $\begin{array}{c}\mathbf{0 , 0 0 5} \\
46 \text { países }\end{array}$ & $\begin{array}{c}\mathbf{0 , 0 1} \\
72 \text { países }\end{array}$ & $\begin{array}{c}\mathbf{0 , 1 3} \\
46 \text { países }\end{array}$ & $\begin{array}{c}\mathbf{0 , 5 0} \\
63 \text { países }\end{array}$ & $\begin{array}{c}\mathbf{0 , 4 8} \\
63 \text { países }\end{array}$ & $\left|\begin{array}{c}\mathbf{0 , 5 3} \\
63 \text { países }\end{array}\right|$ & $\left|\begin{array}{c}\mathbf{0 , 5 5} \\
72 \text { países }\end{array}\right|$ \\
\hline
\end{tabular}

Fuente: cálculos propios. Las entradas B son coeficientes de regresión logística (error estándar entre paréntesis). Variable dependiente dicotómica. Aborto legal. 1: "ampliamente legal"; 0: "altamente restringido" (Singh et al.,2018: 50). Importancia de Dios: escala 1-10. WVS 2005-2014. Médicos c/ 1.000 hab.: OMS, 2016. ${ }^{* \star *} \mathrm{p}<0.001{ }^{* *} \mathrm{p}<0.01{ }^{*} \mathrm{p}<0.05+\mathrm{p}<0.1$ ns: no significativo

Tabla 5 
Un movimiento feminista fuerte y autónomo -un indicador desarrollado por las mismas investigadoras- explica por sí sola el $38 \%$ de la varianza y es un potente predictor en todos los modelos. La presencia parlamentaria de la mujer eleva aún más el poder explicativo (columna 2), pero pierde significación al incorporar las actitudes de igualdad de género y el posmaterialismo (columna 3 ). Un pasado o presente socialista también tiene un efecto relevante, pero negativo. Sumando a esta variable la acción social feminista, la igualdad de género y el posmaterialismo se explica el $76 \%$ de la varianza (columna 6 ). En un modelo alternativo (el 7), la igualdad de género deja de ser significativa frente al impacto combinado del nivel de democracia (positivo) y la religión islámica (negativo).

Para predecir las políticas sobre el aborto (Tabla 5), los países han sido clasificados en las dos grandes categorías de Singh et al. (2018: 50), de acuerdo a si la práctica es "ampliamente legal" o "altamente restringida". Hallamos aquí que ni la movilización feminista, ni la presencia parlamentaria de la mujer -ni la interacción entre ambos- tienen un impacto significativo sobre el aborto legal (columnas 1 a 3). Tampoco tienen relevancia los médicos por habitante y las actitudes de igualdad de género (columnas 4 y 5). En los modelos 4 a 7 vemos que el legado socialista exhibe ahora un efecto positivo y, más que la religiosidad en sí misma, es la presencia de la religión católica -a raíz de los factores institucionales antes discutidos- la que posee un impacto negativo. El grado en que la población justifica el aborto eleva previsiblemente el poder predictivo de los dos últimos modelos.

(1) Higgins, C. (2018). The age of patriarchy: how an unfashionable idea became a rallying cry for feminism today. The Guardian, 22 de junio.

(2) Ver, por ejemplo, The Guardian (2018). The Guardian view on Argentina and abortion: a setback, but not the end, 9 de agosto; Rubio, J. M. (2018). This is why Argentina did not legalize abortion this week. The Washington Post, 11 de agosto.

\section{Bibliografía}

Alesina, A.; Devleeschawer, A.; Easterly, W.; Kurlat, S. y Wacziarg, R. (2003). Fractionalization. Journal of Economic Growth, 8, 155-94.

Amnistía Internacional, Centro de Estudios Legales y Sociales, Católicas por el Derecho a Decidir y Equipo Latinoamericano de Justicia y Género (2018). El derecho a la salud 
sexual y reproductiva de las mujeres en Argentina. Documento presentado ante la Comisión Interamericana de Derechos Humanos. Santo Domingo, 9 de mayo. Recuperado de http://www.cels.org.ar

Asal, V.; Brown, M. y Gibson Figueroa, R. (2008). Structure, Empowerment and the Liberalization of Cross-National Abortion Rights. Politics and Gender, 4(2), 265-84.

Beckwith, K. (2013). The Comparative Study of Women's Movements. En Waylen, G.; Celis, K.; Kantola, J. y Weldon, L. S. (eds.). The Oxford Handbook of Gender and Politics (pp. 411-36). New York: Oxford University Press.

Berer, M. (2017). Abortion Law and Policy Around the World: In Search of Decriminalization. Health and Human Rights Journal, 19(1), 13-27.

Boyle, E. H.; Kim, M. y Longhofer, W. (2015). Abortion Liberalization in World Society, 19602009. American Journal of Sociology, 121(3), 882-913.

Buss, D. E. (1998). Robes, Relics and Rights: The Vatican and the Beijing Conference on Women. Social \& Legal Studies, 7(3), 339-63.

Collins, P. H. y Chepp, V. (2013). Intersectionality. En Waylen, G.; Celis, K.; Kantola, J. y Weldon, S. L. (eds.). The Oxford Handbook of Gender and Politics (pp. 57-87). New York: Oxford University Press.

Cook, R. J.; Erdman, J. N. y Dickens, B. M. (eds.) (2014). Abortion Law in Transnational Perspective. Philadelphia: University of Pennsylvania Press.

Cook, R. J. y Dickens, B. M. (2003). Human Rights Dynamics of Abortion Law Reform. Human Rights Quarterly, 25(1), 1-59.

Doan, L.; Loehr, A. y Millera, L. R. (2014). Formal Rights and Informal Privileges for Same-Sex Couples. American Sociological Review, 79(6), 1172-95.

Dobbin, F.; Simmons, B. y Garrett, G. (2007). The Global Diffusion of Public Policies: Social Construction, Coercion, Competition, or Learning? Annual Review of Sociology, 33, 449-72.

Freedman, L. P. e Isaacs, S. L. (1993). Human Rights and Reproductive Choice. Studies in Family Planning, 24(1), 18-30.

Freedman, E. B. (2002). No Turning Back. The History of Feminism and the Future of Women. New York: Ballantine Books.

Friedman, E. J. (2003). Gendering the Agenda: the Impact of the Transnational Women's Rights Movement at the UN Conferences of the 1990s. Women's Studies International Forum, 26(4), 313-31.

Glendon, M. A. (1996). What happened at Beijing. First Things, January. Recuperado de http://www.firstthings.com 
Glick, P. y Fiske. S. T. (2011). Ambivalent Sexism Revisited. Psychology of Women Quarterly, 35(3), 530-35.

Htun, M. y Weldon, S. L. (2018). The Logics of Gender Justice. New York: Cambridge University Press.

Htun, M. y Weldon, S. L. (2012). The Civic Origins of Progressive Policy Change: Combating Violence against Women in Global Perspective, 1975-2005. American Political Science Review, 106(3), 548-69.

Inglehart, R. F. (2018). Cultural Evolution. Cambridge: Cambridge University Press.

Inglehart, R. F. (2016). How much should we worry? Journal of Democracy, 27(3), 18-23.

Inglehart, R. F. (1997). Modernization and Postmodernization. Princeton: Princeton University Press.

Inglehart, R. F. (1990). Culture Shift in Advanced Industrial Society. Princeton: Princeton University Press.

Inglehart, R. F. (2008). Changing Values among Western Publics, 1970-2006. West European Politics, 31(1-2), 130-46.

Inglehart, R. F.; Ponarin, E. e Inglehart, R. C. (2018). Cultural Change, Slow and Fast. Social Forces, January, 1-28.

Inglehart, R. F. y Welzel, C. (2005). Modernization, Cultural Change, and Democracy. Cambridge: Cambridge University Press.

Inglehart, R. F. y Norris, P. (2003). Rising Tide. Gender Equality and Cultural Change around the World. Cambridge: Cambridge University Press.

James, S. L.; Gubbins, P.; Murray, C. J. y Gakidou, E. (2012). Developing a comprehensive time series of GDP per capita for 210 countries from 1950 to 2015. Population Health Metrics, 10(1), 1-12.

Jorge, J. E. (2018a). Ni "grieta" ni "degradación moral": un contraste empírico del relato político en Argentina. Question, 1(59), 1-33.

Jorge, J. E. (2018b). Valores Democráticos para Tiempos de Crisis. Hallazgos de dos Teorías. Question, 1(57), 1-33.

Jorge, J. E. (2017). Estado de Derecho y Valores Democráticos. Las Direcciones del Cambio Cultural. Question, 1(54), 172-206.

Jorge, J. E. (2016a). La Confianza Interpersonal Revela sus Misterios. ¿La Partícula de Dios? Question, 1(52), 143-74.

Jorge, J. E. (2016b). Teoría de la Cultura Política. Enfocando el Caso Argentino. Question, 1(49), 300-21.

Jorge, J. E. (2015). La Cultura Política Argentina: una Radiografía. Question, 1(48), 372-403. 
Jorge, J. E. (2012). Same-sex marriage in Argentina. Tolerance and discrimination in Political Culture. Journal of Research in Peace, Gender \& Development, 2(3), 60-71.

Jorge, J. E. (2011). El Trabajo de la Democracia. Tolerancia y Discriminación en la Cultura Política Argentina. Question, 1(32), 1-17.

Jorge, J. E. (2010). Cultura Política y Democracia en Argentina. La Plata: Edulp.

Mazur, A. G.; McBride, D. E. y Hoard, S. (2016). Comparative strength of women's movements over time: conceptual, empirical, and theoretical innovations. Politics, Groups, and Identities, 4(4), 652-76.

Mclntosh, C. A. y Finkle, J. L. (1995). The Cairo Conference on Population and Development: A New Paradigm? Population and Development Review, 21(2), 223-60.

Pharr, S. (1988). Homophobia: A Weapon of Sexism. Inverness: Chardon Press.

Reger, J. (2015) Feminism, First, Second, and Third Waves. En Ritzer, C. The Blackwell Encyclopedia of Sociology (pp. 1-10). John Wiley \& Sons.

Ridgeway, C. L. (2011). Framed by Gender. New York: Oxford University Press,

Singh, S.; Remez, L.; Sedgh, G.; Kwok, L. y Onda, T. (2018). Abortion Worldwide 2017: Uneven Progress and Unequal Access. New York: Guttmacher Institute.

Snyder, R. C. (2008). What Is Third - Wave Feminism? A New Directions Essay. Signs: Journal of Women in Culture and Society, 34(1), 175-96.

United Nations (2017). Reproductive Health Policies 2017: Data Booklet. New York: Department of Economic and Social Affairs, Population Division.

United Nations (2014). Abortion Policies and Reproductive Health around the World. New York: Department of Economic and Social Affairs, Population Division.

Weldon, S. L. (2018). Power, exclusion and empowerment: Feminist innovation in political science. Women's Studies International Forum. En prensa.

Welzel, C. (2013). Freedom Rising. New York: Cambridge University Press.

World Health Organization (2018). Global Abortion Policies Database. Recuperado de http://srhr.org/abortion-policies/

World Health Organization (2011). Unsafe abortion. Geneva: WHO. 


\begin{tabular}{|c|c|c|c|c|c|c|c|c|c|c|c|c|c|c|}
\hline \multirow{3}{*}{$\begin{array}{l}\text { Mues } \\
\text { Pais }\end{array}$} & \multirow{2}{*}{\multicolumn{3}{|c|}{ Normas Sex y Fam }} & \multirow{2}{*}{\multicolumn{3}{|c|}{ Igu. de Género }} & & & & & & & & \\
\hline & & & & & & & \multicolumn{2}{|c|}{ NEI } & \multicolumn{2}{|c|}{ ISE 1970} & \multirow{2}{*}{$\begin{array}{l}\text { Pos- } \\
\text { mat }\end{array}$} & \multirow{2}{*}{$\begin{array}{l}\text { Dios } \\
\text { Imp }\end{array}$} & \multirow{2}{*}{$\begin{array}{l}\text { Wel } \\
\text { Sec }\end{array}$} & \multirow{2}{*}{$\begin{array}{l}\text { IDG } \\
2011\end{array}$} \\
\hline & Hom & Abo & Div & Emp & Lid & Univ & 3 & 6 & Ing & EVN TMI & & & & \\
\hline Alemania & 5,9 & 4,5 & 6,3 & 7,4 & 7,2 & 7,7 & 5,6 & 6,5 & 16,0 & $\begin{array}{ll}71 & 22\end{array}$ & 2,7 & 5,3 & 0,41 & 0,09 \\
\hline Argelia & 2,2 & 2,6 & 4,2 & 3,6 & 3,5 & 6,0 & 3,0 & 3,7 & 4,4 & 50146 & 2,0 & 9,6 & 0,36 & 0,52 \\
\hline Argentina & 5,6 & 3,5 & 6,7 & 7,8 & 6,7 & 7,4 & 5,3 & 6,3 & 8,2 & $\begin{array}{ll}66 & 59\end{array}$ & 2,1 & 7,5 & 0,42 & 0,37 \\
\hline Australia & 6,9 & 5,8 & 7,1 & 8,4 & 6,9 & 8,3 & 6,6 & 7,2 & 17,7 & $\begin{array}{ll}71 & 18\end{array}$ & 1,9 & 5,1 & 0,39 & 0,13 \\
\hline Brasil & 4,6 & 2,3 & 6,2 & 8,0 & 6,4 & 7,6 & 4,4 & 5,9 & 4,5 & $\begin{array}{ll}59 & 103\end{array}$ & 2,1 & 9,5 & 0,33 & 0,45 \\
\hline Bulgaria & 4,1 & 5,6 & 6,4 & 6,7 & 5,5 & 7,7 & 5,4 & 6,0 & 3,9 & $\begin{array}{ll}71 & 28\end{array}$ & 1,4 & 5,7 & 0,43 & 0,23 \\
\hline Burkina Faso & 1,8 & 2,4 & 3,5 & 4,7 & 4,6 & 6,0 & 2,6 & 3,8 & 0,6 & 39144 & 1,8 & 9,1 & 0,28 & 0,61 \\
\hline Canada & 5,7 & 4,7 & 6,0 & 8,3 & 7,1 & 8,1 & 5,4 & 6,6 & 17,9 & $\begin{array}{ll}73 & 19\end{array}$ & 2,6 & 7,2 & 0,35 & 0,11 \\
\hline Chile & 5,7 & 3,2 & 7,0 & 7,2 & 6,9 & 7,3 & 5,3 & 6,2 & 4,8 & 62 & 2,5 & 8,2 & 0,41 & 0,35 \\
\hline China & 2,2 & 2,8 & 3,5 & 5,4 & 5,3 & 6,6 & 2,8 & 4,3 & 0,4 & 59 & 1,4 & 3,5 & 0,51 & 0,18 \\
\hline Colombia & 3,4 & 1,9 & 4,3 & 7,4 & 6,7 & 7,7 & 3,2 & 5,2 & 3,6 & 61 & 2,3 & 9,6 & 0,32 & 0,42 \\
\hline Corea del Sur & 3,3 & 3,4 & 4,5 & 4,8 & 5,8 & 7,0 & 3,7 & 4,8 & 3,0 & 62 & 2,1 & 5,4 & 0,45 & 0,09 \\
\hline Ecuador & 2,9 & 2,1 & 3,8 & 6,9 & 6,7 & 7,1 & 2,9 & 4,9 & 3,5 & 58 & 2,1 & 9,3 & 0,32 & 0,42 \\
\hline EE.UU, & 5,4 & 4,8 & 6,2 & 8,3 & 7,1 & 8,0 & 5,5 & 6,6 & 20,6 & 71 & 1,9 & 7,8 & 0,35 & 0,24 \\
\hline España & 7,1 & 5,5 & 7,5 & 8,6 & 7,3 & 7,6 & 6,7 & 7,3 & 11,8 & 72 & 2,2 & 5,1 & 0,43 & 0,10 \\
\hline Etiopia & 1,5 & 2,3 & 2,9 & 9,0 & 7,2 & 7,9 & 2,2 & 5,1 & 0,5 & 43144 & 2,1 & 9,2 & 0,31 & 0,57 \\
\hline Filipinas & 4,5 & 3,1 & 4,0 & 3,6 & 4,7 & 5,7 & 3,8 & 4,2 & 1,8 & $\begin{array}{ll}61 & 56\end{array}$ & 2,2 & 9,5 & 0,32 & 0,45 \\
\hline Finlandia & 5,9 & 5,5 & 6,8 & 8,7 & 7,1 & 7,9 & 6,1 & 7,0 & 13,5 & 70 & 2,4 & 6,0 & 0,40 & 0,07 \\
\hline Francia & 6,5 & 6,5 & 6,9 & 8,0 & 7,6 & 8,9 & 6,6 & 7,4 & 15,7 & 72 & 2,6 & 4,7 & 0,46 & 0,12 \\
\hline Georgia & 1,2 & 2,6 & 3,7 & 4,2 & 4,2 & 7,2 & 2,5 & 3,8 & 4,1 & $\begin{array}{ll}68 & 56\end{array}$ & 1,5 & 9,2 & 0,26 & 0,42 \\
\hline Ghana & 1,4 & 1,6 & 2,4 & 5,2 & 3,4 & 6,7 & 1,8 & 3,4 & 1,0 & 49120 & 1,7 & 9,7 & 0,21 & 0,57 \\
\hline Gran Bretaña & 5,7 & 4,9 & 6,4 & 8,2 & 6,8 & 7,7 & 5,7 & 6,6 & 15,4 & $\begin{array}{ll}72 & 18\end{array}$ & 2,5 & 5,6 & 0,40 & 0,16 \\
\hline Guatemala & 3,1 & 2,3 & 4,7 & 7,9 & 6,6 & 7,3 & 3,4 & 5,3 & 3,3 & 53118 & 1,8 & 9,7 & 0,33 & 0,53 \\
\hline India & 4,1 & 4,5 & 4,1 & 4,0 & 4,5 & 4,7 & 4,2 & 4,3 & 0,8 & $48 \quad 143$ & 2,1 & 6,1 & 0,41 & 0,57 \\
\hline Indonesia & 1,4 & 1,5 & 3,0 & 4,6 & 4,8 & 6,9 & 1,9 & 3,7 & 0,9 & $\begin{array}{lll}55 & 113\end{array}$ & 1,7 & 9,6 & 0,28 & 0,48 \\
\hline Irak & 1,7 & 2,5 & 4,0 & 3,3 & 3,4 & 6,6 & 2,7 & 3,6 & 4,9 & $\begin{array}{ll}58 & 81\end{array}$ & 1,6 & 9,8 & 0,34 & 0,52 \\
\hline Iran & 1,5 & 2,3 & 3,1 & 3,1 & 4,1 & 5,4 & 2,3 & 3,2 & 7,7 & $\begin{array}{ll}51 & 125\end{array}$ & 1,9 & 9,4 & 0,31 & 0,53 \\
\hline Italia & 3,3 & 3,5 & 5,0 & 7,1 & 6,9 & 7,5 & 4,0 & 5,6 & 14,1 & $72 \quad 30$ & 2,5 & 7,8 & 0,33 & 0,12 \\
\hline Japón & 5,1 & 4,8 & 6,2 & 4,5 & 5,8 & 6,6 & 5,4 & 5,5 & 13,7 & 72 & 2,1 & 4,9 & 0,44 & 0,12 \\
\hline Jordania & 1,3 & 1,9 & 3,1 & 2,4 & 3,0 & 6,7 & 2,1 & 3,1 & 2,6 & 60 & 1,3 & 9,8 & 0,18 & 0,49 \\
\hline Kazajistán & 2,2 & 3,5 & 4,8 & 4,6 & 4,5 & 7,0 & 3,5 & 4,4 & 5,1 & 62 & 1,5 & 7,3 & 0,41 & 0,26 \\
\hline Kirguistán & 1,9 & 2,4 & 3,0 & 4,4 & 4,6 & 5,8 & 2,4 & 3,7 & 1,9 & 60 & 1,6 & 8,3 & 0,35 & 0,38 \\
\hline Libano & 3,0 & 3,1 & 4,1 & 5,2 & 4,9 & 6,7 & 3,4 & 4,5 & 12,7 & 66 & 2,1 & 8,3 & 0,42 & 0,40 \\
\hline Libia & 1,9 & 1,8 & 3,3 & 3,1 & 3,2 & 6,2 & 2,3 & 3,2 & 29,9 & 56 & 1,7 & 9,7 & 0,24 & 0,19 \\
\hline Malasia & 2,4 & 2,1 & 2,8 & 3,6 & 4,3 & 5,7 & 2,4 & 3,5 & 2,6 & $\begin{array}{ll}64 & 42\end{array}$ & 1,9 & 9,0 & 0,31 & 0,31 \\
\hline Mali & 2,9 & 3,4 & 4,7 & 3,6 & 3,4 & 4,9 & 3,7 & 3,8 & 0,6 & 32194 & 1,7 & 9,2 & 0,24 & 0,68 \\
\hline Marruecos & 1,3 & 1,8 & 4,3 & 4,1 & 4,1 & 7,3 & 2,4 & 3,8 & 1,7 & $\begin{array}{ll}53 & 120\end{array}$ & 1,5 & 9,9 & 0,20 & 0,53 \\
\hline Mexico & 4,2 & 2,9 & 4,9 & 7,9 & 6,8 & 6,9 & 4,0 & 5,6 & 7,0 & $\begin{array}{ll}61 & 77\end{array}$ & 2,3 & 9,4 & 0,35 & 0,39 \\
\hline Moldavia & 2,3 & 3,2 & 4,5 & 5,4 & 5,2 & 7,2 & 3,3 & 4,6 & 3,1 & $\begin{array}{ll}65 & 49\end{array}$ & 1,7 & 8,1 & 0,47 & 0,26 \\
\hline Nigeria & 1,9 & 2,1 & 2,6 & 3,3 & 3,4 & 5,4 & 2,2 & 3,1 & 1,3 & $\begin{array}{ll}41 & 169\end{array}$ & 2,0 & 9,0 & 0,30 & $\mathrm{~s} / \mathrm{d}$ \\
\hline
\end{tabular}




\begin{tabular}{|c|c|c|c|c|c|c|c|c|c|c|c|c|c|c|c|}
\hline \multirow{2}{*}{ Pais } & \multicolumn{3}{|c|}{ Normas Sex y Fam } & \multicolumn{3}{|c|}{ Igu. de Género } & \multicolumn{2}{|c|}{ NEI } & \multicolumn{3}{|c|}{ ISE 1970} & \multirow{2}{*}{$\begin{array}{l}\text { Pos- } \\
\text { mat }\end{array}$} & \multirow{2}{*}{$\begin{array}{l}\text { Dios } \\
\text { Imp }\end{array}$} & \multirow{2}{*}{$\begin{array}{l}\text { Wel } \\
\text { Sec }\end{array}$} & \multirow{2}{*}{$\begin{array}{l}\text { IDG } \\
2011\end{array}$} \\
\hline & Hom & Abo & Div & Emp & Lid & Univ & 3 & 6 & Ing & EVN & TMI & & & & \\
\hline Noruega & 7,8 & 6,7 & 7,3 & 9,2 & 8,4 & 9,5 & & 8,1 & 17,9 & 74 & 13 & 2,8 & 4,2 & 0,46 & 0,06 \\
\hline Nueva Zelanda & 5,9 & 5,2 & 6,6 & 8,6 & 7,1 & 7,9 & 5,9 & 6,9 & 15,9 & 71 & 17 & 2,2 & 5,4 & 0,39 & 0,17 \\
\hline Paises Bajos & 7,9 & 6,5 & 7,2 & 8,5 & 7,5 & 8,2 & 7 & 7,6 & 18,4 & 74 & 13 & & 4,4 & 0,43 & 0,05 \\
\hline Pakistan & 1,5 & 1,5 & 2,2 & 3,0 & 3,7 & 5,1 & & 2,8 & 1,0 & 53 & 144 & 4 & 9,6 & 0,30 & 0,57 \\
\hline Peru & 3,7 & 2,4 & 4,8 & 7,5 & 7,2 & 7,3 & 3,6 & 5,5 & 5,2 & 54 & 104 & 0 & 8,9 & 0,40 & 0,41 \\
\hline olonia & 3,6 & 3,1 & 4,9 & 6,8 & 6,0 & 7,2 & 3,9 & 5,2 & 6,2 & 70 & 32 & 2,2 & 8,0 & 0,33 & 0,15 \\
\hline Ruanda & 1,5 & 2,2 & 2,6 & & 5,5 & 6,2 & & 3,8 & 0,7 & 44 & 131 & 7 & 7,7 & 35 & 0,43 \\
\hline umania & 2 & 2,9 & & 5,2 & 5,8 & 7,5 & & 4,6 & 4,0 & 68 & 48 & 0 & 8,9 & 0 & 0,36 \\
\hline Rusia & 2,5 & 4,4 & 6,0 & 5,8 & 4,8 & 6,7 & 4 & 5,0 & 9,9 & 68 & 31 & 6 & 6,7 & 0,49 & 0,31 \\
\hline Singapur & 3,5 & 3,8 & & 5 & 5,6 & 6,7 & & 4 & 7,6 & 68 & 22 & 1 & 7,0 & & 0,09 \\
\hline udáfrica & 4,2 & 4,0 & 4 & 6,2 & 5,3 & 6,3 & & 5,1 & 6,8 & 56 & 88 & 1 & 8,1 & & 0,41 \\
\hline Suecia & 8,2 & 7 & 8 & 9,6 & 7,9 & 8 , & 8 & 8,4 & 18,0 & 75 & 11 & & 3,7 & 0,50 & 0,05 \\
\hline Suiza & 7,3 & 5,5 & 6,9 & 7,3 & 7,6 & 8, & 6 & 7,1 & 25,5 & 73 & 15 & 8 & 6,4 & & 0,06 \\
\hline Tailandia & 2,9 & 1,9 & 3,4 & 5,8 & 5,2 & 6,6 & 2 , & 4,3 & 1,6 & 59 & 72 & 2,0 & 4,2 & & 0,32 \\
\hline Trinidad y Tob & 1,7 & 2,2 & & 7,0 & 6,8 & 8,4 & & 5,0 & 10,2 & 65 & 44 & & 9,7 & & 0,35 \\
\hline Túnez & 1,1 & 2,0 & 3, & 3,0 & 3,5 & 7,0 & 2 , & 3,4 & 2,4 & 51 & 122 & 0,9 & 9,7 & & 0,31 \\
\hline Turquia & 1,7 & 2,1 & 3,2 & 3,8 & 4,1 & 6,6 & 2 & 3,6 & 5,0 & 52 & 127 & 2,1 & 9,3 & 0,24 & 0,37 \\
\hline Ucrania & 2 & 3,8 & & 6,2 & 5,1 & 7 & & 5,0 & 5,9 & 70 & 28 & 7 & 7,2 & 0,47 & 0,33 \\
\hline Jruguay & 6,3 & 3,9 & 7,4 & 7,3 & 8,3 & 7,7 & & 6,8 & 5,4 & 69 & 49 & 2,4 & 6,7 & 0,41 & 0,32 \\
\hline Vietnam & 1,9 & 2,4 & 2,5 & 5,3 & 5,2 & 7,0 & 2,3 & 4,0 & 0,5 & 60 & 54 & 1,9 & 4,8 & 0,28 & 0,33 \\
\hline emen & 1,5 & 2,4 & 3 , & 2,6 & 2,8 & 5,5 & 2 & 3,1 & 0,8 & 41 & 219 & 1,1 & 9,9 & 0,28 & 0,82 \\
\hline ambia & 2,6 & 3,2 & 4,6 & 6,2 & 5,4 & 7,1 & 3,5 & 4,8 & 2,1 & 49 & 108 & 2,0 & 9,2 & 0,37 & 0,57 \\
\hline imbabwe & 1,8 & 2,1 & 3,2 & 6,5 & 4,9 & 7,2 & 2,4 & 4,3 & 0,6 & 55 & 72 & 2,1 & 9,6 & 0,29 & 0,57 \\
\hline
\end{tabular}

Notas. Cálculos propios a partir de la base de la WVS, excepto ISE e IDG. Normas sexuales y familiares: justificación de la homosexualidad (Hom), el aborto (Abo) y el divorcio (Div). Promedio en escala 1-10 (justificación creciente).Igualdad de Género: los hombres tienen prioridad para los empleos (Emp), los hombres son mejores líderes que las mujeres (Lid), la educación universitaria es más importante para un hombre que para una mujer (Univ). Promedio en escala 1-10 (desacuerdo creciente). Normas de Elección Individual (NEI). 3 ítems: promedio de las tres normas sexuales y familiares. 6 ítems: promedio de los 3 ítems anteriores y los 3 indicadores de igualdad de género. ISE 1970: componentes del Índice de Seguridad Existencial en 1970. Ing: Ingreso per cápita PPA en u\$s internacionales constantes de 2005 (en miles). Estimación del Institute for Health Metrics and Evaluation (IHME) de la Universidad de Washington (Seattle). Tomado de James et al, 2012. EVN: Esperanza de Vida al Nacer (años). TMI: Tasa de Mortalidad Infantil (c/ 1.000 nacidos vivos). Datos de la Organización Mundial de la Salud. Posmat: Índice de Posmaterialismo de 12 ítems. Escala 0-5. Dios imp.:Importancia de Dios en la vida del entrevistado. Escala 1-10. Welzel Sec.: Índice de Valores Seculares de Welzel. Escala 0-1. IDG: Índice de Desigualdad de Género del PNUD. Año 2011. Escala 0-1.

Tabla A 


\section{Paises relevados por Latinobarómetro}

\begin{tabular}{lrrrrrr} 
País & Abo & Lid & IDG & \multicolumn{3}{c}{ ISE $\mathbf{1 9 7 0}$} \\
& $\mathbf{2 0 1 5}$ & $\mathbf{2 0 0 9}$ & $\mathbf{2 0 1 1}$ & Ing & EVN & TMI \\
Argentina & 3,2 & 7,4 & 0,37 & 8,2 & 66 & 59 \\
Bolvia & 2,7 & 6,9 & 0,50 & 2,9 & 46 & 144 \\
Brasil & 3,0 & 8,4 & 0,45 & 4,5 & 59 & 103 \\
Chile & 4,4 & 7,8 & 0,35 & 4,8 & 62 & 67 \\
Colombia & 2,7 & 7,3 & 0,42 & 3,6 & 61 & 70 \\
Costa Rica & 2,3 & 7,9 & 0,32 & 5,4 & 66 & 62 \\
R. Dominicana & 2,6 & 6,8 & 0,49 & 2,6 & 59 & 87 \\
Ecuador & 2,4 & 7,0 & 0,42 & 3,5 & 58 & 96 \\
El Salvador & 1,9 & 7,5 & 0,44 & 4,1 & 55 & 107 \\
Guatemala & 3,1 & 6,7 & 0,53 & 3,3 & 53 & 118 \\
Honduras & 2,1 & 7,2 & 0,51 & 2,4 & 53 & 102 \\
México & 3,2 & 7,4 & 0,39 & 7,0 & 61 & 77 \\
Nicaragua & 2,9 & 7,4 & 0,48 & 3,4 & 54 & 117 \\
Panamá & 2,9 & 7,3 & 0,52 & 4,3 & 66 & 51 \\
Paraguay & 2,3 & 7,2 & 0,49 & 2,3 & 66 & 58 \\
Perú & 3,2 & 7,4 & 0,41 & 5,2 & 54 & 104 \\
Uruguay & 4,5 & 7,8 & 0,32 & 5,4 & 69 & 49 \\
Venezuela & 2,0 & 7,8 & 0,47 & 10,5 & 65 & 48 \\
& & Tabla B & & & &
\end{tabular}

